\title{
Maturation and Maceration Effects on Tropical Red Wines Assessed by Chromatography and Analysis of Variance - Principal Component Analysis
}

\author{
Janaína A. Barbará, ${ }^{a}$ Érica A. S. Silva,${ }^{b}$ Aline C. T. Biasoto, ${ }^{c}$ Adriano A. Gomes, ${ }^{a}$ \\ Luiz C. Correa, ${ }^{c}$ Patrícia C. S. Leão ${ }^{c}$ and Cláudia A. Zini ${ }^{\oplus *, a}$ \\ ${ }^{a}$ Instituto de Química, Universidade Federal do Rio Grande do Sul, \\ Avenida Bento Gonçalves, 9500, 91501-970 Porto Alegre-RS, Brazil \\ ${ }^{b}$ Departamento de Química, Universidade Federal de São Paulo, \\ Rua Prof. Arthur Riedel, 275, Jardim Eldorado, 09972-270 Diadema-SP, Brazil
}

'Empresa Brasileira de Pesquisa Agropecuária (Embrapa), BR 428, km 152, 56302-970 Petrolina-PE, Brazil

\begin{abstract}
Effects of grape maturity, maceration length during winemaking and interaction of both of them on physicochemical parameters, phenolic and volatile composition were investigated in tropical Syrah wines with the aim of finding the best conditions to produce wines that are rich in phenols and positive aroma active compounds. A headspace solid phase micro extraction and gas chromatography with mass spectrometry (HS-SPME-GC-MS) method was improved and validated for the analysis of 41 volatiles. Principal component analysis (PCA) and analysis of variance (ANOVA)-PCA coupled with inspection of statistically significant loadings were important to access the effects of maturation and maceration on wine composition. Wines made from riper grapes (21-23 ${ }^{\circ}$ Brix) stood out in relation to color intensity, total phenolic compounds, and presented high levels of anthocyanins, flavonols, procyanidin A2, and linalool (floral). Thirty days of maceration were linked to higher levels of some flavan-3-ols, gallic acid, a few esters (fruity) and alcohols, (E)-nerolidol (floral), while nonanoic acid (unpleasant aroma) reduced its concentration with prolonged maceration.
\end{abstract}

Keywords: Brazilian red wine, Vitis vinifera L. Syrah wines, analysis of variance, principal component analysis, volatile compounds, phenolic compounds, Submiddle São Francisco Valley

\section{Introduction}

Most of the compounds that determine the quality of the wines are synthesized during the grape maturation period. This physiological period begins in the véraison (change of the color of the grape berries), ends with the maturation of the berry, and depends on environmental conditions as well as on agricultural practices employed. ${ }^{1}$ The technological maturation includes soluble solids content of about $21-22{ }^{\circ}$ Brix and titratable acidity of $6-8 \mathrm{~g} \mathrm{~L}^{-1} \cdot{ }^{2} \mathrm{In}$ addition to technological maturation, phenolic and aromatic maturations also play an important role in the achievement of wine quality. They do not necessarily occur at the same time, being therefore necessary to control them separately to determine the ideal time for grape harvest. In general, the grape reaches ideal phenolic maturation when the content

*e-mail: cazini@iq.ufrgs.br, claudialcaraz@gmail.com of anthocyanins and tannins in the skins is maximal, while the tannin content of the seed begins to reduce and then becomes relatively constant. In this stage, the equilibrium between the tannins of the skins and the seeds occurs, characterizing a wine "harmonic" to the palate, which presents balanced astringency and bitterness. ${ }^{2}$

Some of the volatile compounds and their precursors are also synthesized during the ripening of the grapes and are important for the characteristic aroma of a variety, of a region or vinification procedures. The concentration of volatiles in wines will also depend on different factors, such as climate, region, soil, grape variety, vineyard management practices, winemaking techniques and yeasts. ${ }^{3}$ They originate from the catabolism of fatty acids, amino acids, sugars, pectin and carotenoids of the berries, resulting in compounds of different chemical classes. Aromatic maturation is characterized as the stage where the grape gradually loses its herbaceous and vegetable aromas, while at the same 
time acquires fruity aromas. ${ }^{2}$ In order to be perceived by the human nose, the concentration of a volatile compound should be higher than its perception threshold and therefore its odor activity value $(\mathrm{OAV})$ should be higher than one. Moreover, the use of OAV allows a quantitative approach related to the contribution of volatiles to the aroma of wines, while a qualitative evaluation can be made based on the descriptors of each compound. A compound with an OAV $>1$ is supposed to contribute to the final aroma of a wine. ${ }^{4}$

Classical parameters, such as sugar content, total acidity and $\mathrm{pH}$, are often used to determine the ideal maturation stage. However, a more detailed analysis of phenolic and volatile compounds has been used to specifically monitor grape varietal characteristics and to achieve the maximum wine quality. The ideal levels of soluble solids and acidity in grapes can be obtained in a shorter period, with a combination of high temperatures and intense solar radiation on the vine. However, aromatic and phenolic maturation may not be achieved under these same conditions. Consequently, the investigation of all these parameters is important for the achievement of a good wine quality. ${ }^{5}$

In addition to optimum maturation, the maceration process is a critical step for the definition of the wine style and also for the production of high quality wines, as it leads to increased color stability, body, and improved tastes and flavors. Longer maceration periods may be convenient when wines are intended for ageing or when it is necessary to circumvent insufficient phenolic maturation of harvested grapes. During maceration there is a considerable increase in the content of aroma active compounds due to the contact time of the grape skins with the wine must. ${ }^{3}$ Tannins, anthocyanins and other types of phenolic compounds, as well as nitrogen compounds, minerals, sugars and polysaccharides are also extracted from the grapes. Prolonged maceration provides higher concentrations of wine tannins, and, consequently, of condensed anthocyanins with tannins, forming complexes that impart higher color stability than that produced by monomeric anthocyanins. These compounds are the main responsible for the color of wines aged in oak barrels. ${ }^{6}$

The effect of the maturation degree of the grapes on phenolic compounds has been investigated in Italian Nebbiolo grapes. ${ }^{7}$ The impact of different maceration periods on phenolic composition has also been studied in Turkish Karaoglan (Vitis vinifera L.) wines. ${ }^{8}$ Australian Cabernet Sauvignon ${ }^{9}$ was examined in relation to the effect of the grape maturation on volatile composition of wines. The influence of the maceration periods during the winemaking on volatile composition was investigated for the same Karaoglan Turkish wines. ${ }^{10}$ All these studies included physicochemical parameters of the wines.
However, there is a lack of research that would consider the influence of both factors (grape ripeness degree at harvest and maceration time) and the effect of their interaction on the quality of tropical climate wines. Furthermore, it is also important to evaluate and link, all at once, the former factors with physicochemical parameters, phenolics and volatiles, as well as to assess the interaction between these variables.

The statistical approach adopted was the analysis of variance-principal component analysis (ANOVA-PCA), which distinguishes the systematic data variation due to the levels of the factors with respect to the variability of the residual error. It combines the advantages of both techniques in which each of the factors together with residual error matrices are subjected to PCA decomposition. The idea behind the ANOVA-PCA approach is that if a factor is significant, it should be the largest variance of the data; this means that the samples should be grouped along PC1 according to the levels of the respective factor. If the separation occurs along PC2, this is an indication that the factor significance is not so pronounced. On the other hand, if the separation is observed in the $\mathrm{PC} 1$ versus $\mathrm{PC} 2$ plane, the interaction between factors can be significant. ${ }^{11}$ A few examples of successful applications of ANOVA-PCA approach have been reported, e.g., the optimization of a voltammetric method for $\mathrm{Cd}, \mathrm{Cu}, \mathrm{Pb}$ and $\mathrm{Zn}$ determination in biodiesel samples ${ }^{12}$ and discrimination between cultivars and treatments of broccoli using mass spectral data. ${ }^{13}$ It has also been applied to compare the overall impact of berry shriveling and harvest dates on Shiraz grape (the term Shiraz is commonly used in Australia instead of Syrah) and wine chemical composition. As far as the authors are aware, this is the first time it is applied to the investigation of the effects of grape maturation and maceration on the composition of Syrah wines..$^{14}$

This work is devoted to study the influence of different stages of grape maturation at the time of harvest and also to investigate the duration of maceration during winemaking in the composition of the red wines of Syrah cultivar grown in a tropical climate region. We also report the successful use of ANOVA-PCA to evaluate the significance of each factor studied, as well as the interaction between both of them. In addition, a gas chromatography-mass spectrometry (GC-MS) method was improved and validated to analyze volatiles compounds in Syrah wines headspace.

\section{Experimental}

\section{Experimental design and samples}

Syrah grapes were obtained from a private experimental area (latitude: $9^{\circ} 16^{\prime} \mathrm{S}$, longitude: $40^{\circ} 52^{\prime} \mathrm{S}$; altitude: $413.5 \mathrm{~m}$ ), 
located in the city of Casa Nova, State of Bahia, Brazil. Syrah vines were displayed in vertical shoot positioning and drip-irrigated. The treatments were arranged in the field according to a split plot design, where the main treatments were represented by three different dates of harvest and the secondary treatments by three periods of maceration during the winemaking. The experimental planning was carried out in randomized blocks design with three treatments performed with three repetitions per treatment, in which every single block was composed by 48 plants, providing 432 experiments. Figure S1 (Supplementary Information (SI) section) shows the design of the field experiments. The three dates of grape harvest occurred during consecutive weeks from June to July 2013, at intervals of seven days, which corresponded to 113 days after pruning (DAP) for grapes of treatment $1\left(\mathrm{~T}_{1}\right)$. The total soluble solid content for $\mathrm{T}_{1}$ grapes was $19.0^{\circ} \mathrm{Brix}$; for $\mathrm{T}_{2}$ grapes (120 DAP), $21.0^{\circ} \mathrm{Brix}$ and for $\mathrm{T}_{3}$ grapes (127 DAP), $23.0^{\circ}$ Brix. Eight combinations of experimental treatments were provided due to different stages of grapes maturation and lengths of maceration $\left(\mathrm{M}_{1}\right.$, $\mathrm{M}_{2}, \mathrm{M}_{3}: 10,20$, 30 days, respectively): $\mathrm{T}_{1} \mathrm{M}_{1}, \mathrm{~T}_{1} \mathrm{M}_{2}, \mathrm{~T}_{2} \mathrm{M}_{1}$, $\mathrm{T}_{2} \mathrm{M}_{2}, \mathrm{~T}_{2} \mathrm{M}_{3}, \mathrm{~T}_{3} \mathrm{M}_{1}, \mathrm{~T}_{3} \mathrm{M}_{2}$ and $\mathrm{T}_{3} \mathrm{M}_{3}$ (Table $\mathrm{S} 1$, SI section).

\section{Winemaking}

Vinifications were performed in triplicate by a traditional method. ${ }^{15}$ Grapes were stored in a cold chamber at $10 \pm 2{ }^{\circ} \mathrm{C}$ for $12 \mathrm{~h}$ and then were destemmed and lightly crushed to obtain the wine musts. The musts were transferred to glass carboys $(20 \mathrm{~L})$ closed with cylindrical airlock glass valves with floating bubbler and $100 \mathrm{mg} \mathrm{L}^{-1}$ of $\mathrm{K}_{2} \mathrm{~S}_{2} \mathrm{O}_{5}$ (Synth, São Paulo, SP, Brazil) were added as preservative. Commercial yeast Maurivin PDM $^{\circledR}$ (MauriYest PTY LTD, Queensland, Australia) Saccharomyces cerevisiae var. bayanus $\left(350 \mathrm{mg} \mathrm{L}^{-1}\right)$ and Gesferm Plus ${ }^{\circledR}$ (Amazon Group Ltda., Bento Gonçalves, $\mathrm{RS}$, Brazil) as fermentation activator $\left(200 \mathrm{mg} \mathrm{L}^{-1}\right)$ were added to start fermentation. Alcoholic fermentation was carried out under controlled temperature $\left(25 \pm 1^{\circ} \mathrm{C}\right)$ and was completed when the density was constant and the residual sugar concentration was below $3 \mathrm{~g} \mathrm{~L}^{-1}$. Malolactic fermentation started naturally at $17 \pm 1{ }^{\circ} \mathrm{C}$ and run for 30 days, until all malic acid was converted to lactic acid, as visualized by paper chromatography. Tartaric stabilization of wines was achieved in a cold chamber at $0{ }^{\circ} \mathrm{C}$ over a period of a month. Before bottling, the content of free sulfur dioxide was corrected with $\mathrm{K}_{2} \mathrm{~S}_{2} \mathrm{O}_{5}$ to $30 \mathrm{mg} \mathrm{L}^{-1}$.

\section{Analytical reagents and supplies}

Folin-Ciocalteau reagent were obtained from Merck
(Darmstadt, Germany). Methyl alcohol, acetonitrile (both high performance liquid chromatography (HPLC) grade) and orthophosphoric acid were supplied by Vetec Química Fina Ltda. (Rio de Janeiro, RJ, Brazil). Authentic standards with purity $\geq 99 \%$ were purchased from Sigma-Aldrich (St. Louis, USA): ethyl butanoate, ethyl hexanoate, ethyl octanoate, ethyl decanoate, diethyl butanedione, hexanoic acid, octanoic acid, phenyl methanol, 2-phenyl ethanol, linalool, $(E)$-nerolidol, methyl nonanoate, $\alpha$-methyl benzyl alcohol, 2-methyl valeric acid, isocineol, chlorogenic, $p$-coumaric, caffeic, gallic and ferulic acids. Malvidin-3-O-glucoside, cyanidin3-O-glucoside, delphinidin-3-O-glucoside, peonidin3-O-glucoside, pelargonidin-3-O-glucoside, quercetin, rutin, myricetin, kaempferol-3-O-glucoside, isorhamnetin 3-O-glucoside, (+)-catechin, (-)-epicatechin, (-)-epicatechin gallate, (-)-epigallocatechin gallate, procyanidin A2, procyanidin B1, procyanidin B2 and trans-resveratrol were obtained from Extrasynthese (Genay, France). Wine model solution was prepared with ethyl alcohol (Nuclear, São Paulo, SP, Brazil) $14 \%$ in Milli-Q deionized water (purification system Millipore, Bedford, USA), $6 \mathrm{~g} \mathrm{~L}^{-1}(+)$-tartaric acid (Synth, São Paulo, SP, Brazil), and the $\mathrm{pH}$ was adjusted to 3.5 with sodium hydroxide (Nuclear, São Paulo, SP, Brazil). Sodium chloride $(\mathrm{NaCl})$ was purchased from Nuclear (São Paulo, SP, Brazil) and was oven dried at $150^{\circ} \mathrm{C}$ for two hours. The solid phase micro extraction (SPME) fiber used was divinylbenzene/carboxen/polydimethylsiloxane (DVB/CAR/ PDMS 50/30 $\mu \mathrm{m}$ StableFlex, Supelco, Bellefonte, USA).

\section{Analysis of wines}

Classical analysis, total phenolic and total monomeric anthocyanin content

The analyses of Syrah wines was carried out by determining $\mathrm{pH}$, ethanol and dry extract contents in an electronic hydrostatic scale Super Alcomat after previous wine distillation in digital enological distiller Super Dee (Gibertini, Milan, Italy). The color intensity was determined through molecular absorbance measured at 420, 520 and $620 \mathrm{~nm}$ with a UV-Vis spectrophotometer (model Genesys 10S UV-vis, Thermo Fisher Scientific, Waltham, USA). Total titratable acidity (expressed as $\mathrm{g} \mathrm{L}^{-1}$ of tartaric acid) was determined through potentiometric titration. ${ }^{16}$ Total polyphenol index was measured with the same spectrophotometer formerly mentioned, at $280 \mathrm{~nm} .{ }^{17}$ The total phenolic content was also determined spectrophotometrically at $760 \mathrm{~nm}$, using the Folin-Ciocalteu reagent. ${ }^{18}$ The analyses of total monomeric anthocyanins were carried out using the $\mathrm{pH}$-differential method ${ }^{19}$ at 520 and $700 \mathrm{~nm}$ and concentrations of these pigments were expressed as cyanidin-3-O-glucoside equivalents in $\mathrm{mg} \mathrm{L}^{-1}$. 
Analyses of phenolic compounds of Syrah wines using high performance liquid chromatography with diode array and fluorescence detectors (HPLC-DAD-FD)

Quantification of 23 phenolic compounds followed a formerly validated method described elsewhere, ${ }^{20}$ using a liquid chromatograph Waters model 2695 Alliance system (Milford, USA) coupled to a DAD (220, 320, 360 and $520 \mathrm{~nm}$ ) and an FD (320 nm for emission). A Gemini-NX C18 $(150 \times 4.60 \mathrm{~mm} \times 3 \mu \mathrm{m})$ column and a Gemini-NX C18 pre-column $\left(4.0 \times 3.0 \mathrm{~mm}\right.$, Phenomenex ${ }^{\circledR}$, Torrance, CA, USA) were used. The oven temperature was kept at $40{ }^{\circ} \mathrm{C}$, the mobile phase flow was $0.5 \mathrm{~mL} \mathrm{~min}^{-1}$ and two aqueous mobile phases $[0.85 \%$ orthophosphoric acid solution (A) and acetonitrile (B)] were utilized. The gradient program was as follows: $0 \mathrm{~min}, 100 \%$ of $\mathrm{A} ; 10 \mathrm{~min}, 93 \%$ of $\mathrm{A}$; $20 \mathrm{~min}, 90 \%$ of $\mathrm{A} ; 30 \mathrm{~min}, 88 \%$ of $\mathrm{A} ; 40 \mathrm{~min}, 77 \%$ of $\mathrm{A}$; $45 \mathrm{~min}, 65 \%$ of $\mathrm{A}$, and $55 \mathrm{~min}, 100 \%$ of B. Undiluted samples were filtered through a nylon membrane $(0.45 \mu \mathrm{m}$ pores size) and $10 \mu \mathrm{L}$ of the samples were subsequently injected in the HPLC. The software used for data acquisition and treatment was the Empower ${ }^{\mathrm{TM}} 2$ (Waters, Milford, USA). The DAD detected gallic acid, (-)-epicatechin gallate and (-)-epigallocatechin gallate and procyanidin $\mathrm{B} 1$ at $220 \mathrm{~nm}$; trans-resveratrol, caffeic acid, cinnamic acid, $p$-coumaric acid and chlorogenic acid at $320 \mathrm{~nm}$; the flavonols kaempferol-3-O-glucoside, myricetin, quercetin, rutin, and isorhamnetin-3-O-glucoside at $360 \mathrm{~nm}$; and the anthocyanins malvidin-3-O-glucoside, cyanidin3-O-glucoside, peonidin-3-O-glucoside, delphinidin$3-O$-glucoside, and pelargonidin-3-O-glucoside at $520 \mathrm{~nm}$. The FD was employed for (+)-catechin, procyanidin B2, procyanidin A2 and (-)-epicatechin.

Analyses of volatile compounds of Syrah wines using headspace solid phase micro extraction (HS-SPME) and gas chromatography with mass spectrometric analyses (GC-MS)

In order to obtain a matrix that would be similar to wine with respects to ethanol (14\%) and acidity ( $\mathrm{pH}$ ranging to 3.3 from 3.5), a wine model solution was prepared with $6 \mathrm{~g} \mathrm{~L}^{-1}$ of (+)-tartaric acid (Synth, São Paulo, SP, Brazil), 14\% of ethanol in Milli-Q deionized water (purification system Millipore, Bedford, MA, USA) and the $\mathrm{pH}$ was adjusted to 3.5 with sodium hydroxide (Nuclear, São Paulo, SP, Brazil). ${ }^{21}$

The procedure of HS-SPME-GC-MS has been formerly reported by Welke et al. ${ }^{21}$ In short, one milliliter of wine samples and $0.3 \mathrm{~g}$ of $\mathrm{NaCl}$ were placed in $20 \mathrm{~mL}$ glass headspace vials with screw caps and teflon septa. HS-SPME was carried out at $55^{\circ} \mathrm{C}$ for 45 min using a $2-\mathrm{cm}$ DVB/CAR/PDMS 50/30 $\mu \mathrm{m}$ fiber without magnetic stirring. The SPME fiber was then desorbed in the GC inlet at $250{ }^{\circ} \mathrm{C}$ for 5 min. Sampling was performed using a Combi PAL sampler (CTC Analytics, Zwingen, Switzerland).

The GC-MS system was a Shimadzu (Kyoto, Japan) equipped with a spectrometry detector QP 2010. The columns were a DB-Wax (100\% polyethylene glycol) and a DB-5 (5\% phenyl, 95\% polydimethylsiloxane), both purchased from J\&W Scientific Inc. (Folsom, CA, USA) and measuring $30 \mathrm{~m} \times 0.25 \mathrm{~mm} \times 0.25 \mu \mathrm{m}$. Helium carrier gas $(99.9999 \%$ purity, White Martins, Porto Alegre, RS, Brazil) was used with a flow of $1 \mathrm{~mL} \mathrm{~L}^{-1}$ and a splitless time of 1.0 min during desorption. Oven temperature program conditions were as follow: $40{ }^{\circ} \mathrm{C}$ for $5 \mathrm{~min}$, programmed at $3{ }^{\circ} \mathrm{C} \mathrm{min}^{-1}$ to $200{ }^{\circ} \mathrm{C}$, and then raised to $250{ }^{\circ} \mathrm{C}$, at a rate of $20^{\circ} \mathrm{C} \mathrm{min}^{-1}$, where it remained for $3 \mathrm{~min}$. The injector, transfer line and ion source temperature were at $250{ }^{\circ} \mathrm{C}$. The mass spectrometry detector included electron ionization at $70 \mathrm{eV}$ and mass range of $\mathrm{m} / \mathrm{z} 45-450$, in the full scan mode. The area of each peak was determined by GC-Solution software (Shimadzu, Kyoto, Japan). Chromatographic analyses were carried out in triplicate for each sample.

Positive identification of the quantified compounds was achieved by comparison of the experimentally acquired retention times and mass spectra with those of authentic standards. Tentative identification of compounds was achieved comparing experimentally acquired mass spectra and retention indices (RI) with the ones from literature. A maximum difference of 20 units for RI and $80 \%$ of minimum spectrum similarity were required. RI were determined according to Kovats $^{22}$ for isothermal conditions and to Van den Dool and $\mathrm{Kratz}^{23}$ for oven programmed temperature. The linearity of the method was verified through calibration curves that were constructed with triplicate extractions/analyses of wine model solutions fortified in concentration ranges that were chosen according to previously published works. ${ }^{24}$ Repeatability (intra-day precision) was evaluated through relative standard deviations determined with three successive injections in the same day. Intermediate precision (inter-day) was assessed throughout three different days $(n=9)$ and recovery was verified with synthetic wine spiked with standard compounds. Determinations were performed in two different levels of concentration (low and high), which were chosen because they correspond to the concentrations of the limits of each compound curve. ${ }^{24}$ Limits of detection was calculated as $3 \mathrm{~s} / \mathrm{S}$ and the limit of quantification as $10 \mathrm{~s} / \mathrm{S}$, where $\mathrm{s}$ is the standard deviation of seven replicates at the lowest point of the curve and $\mathrm{S}$ is the angular coefficient of the calibration curve.

\section{Chemometric procedures and data analysis}

The influence of factors degree of maturation and maceration time on wine quality was assessed by means of 
a homemade ANOVA-PCA routine that was implemented in MatLab environment as described elsewhere. ${ }^{25}$ Before submitting the data to ANOVA-PCA, outlier presence was checked using the concept of extreme samples in projection of PCA, generating a robust threshold based on data driven soft independent modeling by class analogy (DD-SIMCA) classifier. DD-SIMCA calculation was carried out using a graphical user interface available elsewhere. ${ }^{26}$ Briefly, each data matrix $\mathbf{X}$ (physicochemical parameters, volatile and phenolic compounds), previously autoscaled, was submitted to decomposition into principal components. Score distance (SD) and orthogonal distance (OD) were combined in a new parameter ' $c$ ', called the total distance. Total distance is the scaled sum of $\mathrm{SD}_{\mathrm{i}}$ and $\mathrm{OD}_{\mathrm{i}}$. The ' $\mathrm{c}$ ' value presents distribution of type $\chi^{2}$, with $\mathrm{N}_{\mathrm{SD}}+\mathrm{N}_{\mathrm{OD}}$ degrees of freedom. It was used to generate an acceptance area which distinguishes regular, extreme and outlier samples. In addition, scaling factors and degrees of freedom are obtained using a data driven approach. For all cases the data were previously autoscaled.

Significant loadings were assessed at $95 \%$ confidence following the approach described by Yamamoto et al. ${ }^{27}$ A loading value related to variables can be interpreted as a measure of the correlation coefficient between these variables and a principal component (PC). This allows to estimate a parameter $\sigma$ with a $t$ distribution ( $\mathrm{n}-2$ degrees of freedom).

\section{Results and Discussion}

\section{Outlier detection and general comments}

Wines from experiments $\mathrm{T}_{1} \mathrm{M}_{3}$ (harvest at $113 \mathrm{DAP}$ and 30 days of maceration) resulted in an unacceptable level of wine astringency, probably due to a high concentration of

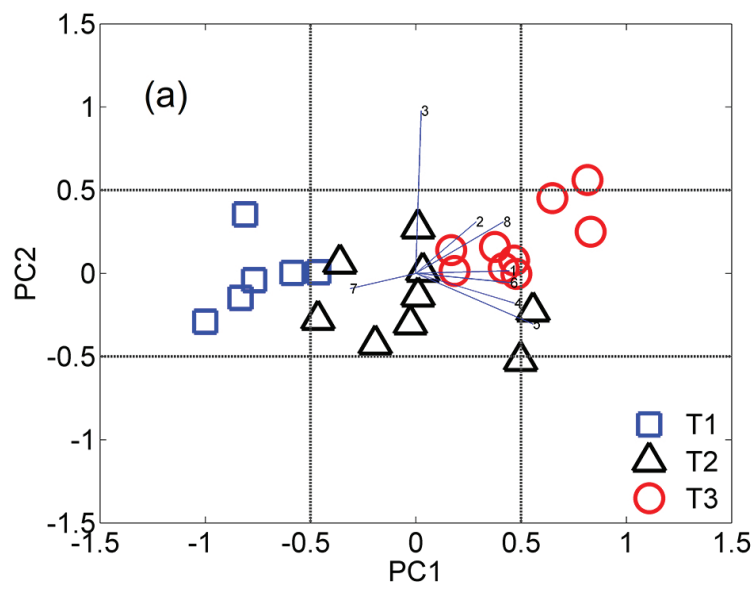

tannins from the seeds with less degree of polymerization associated with their long maceration time..$^{15}$ Therefore, they were removed from the data set.

Figures S2a-c (SI section) present the results of DD-SIMCA where it is possible to see that outliers were not detected in the data set, at $95 \%$ confidence. All samples presented a ' $c$ ' value designated as regular. The ANOVA-PCA was conducted for physicochemical parameters, volatile, and phenolic compounds. For the last two classes of compounds, the sums of subclasses were not considered for this approach. Loadings (blue lines) that surpassed the black vertical and horizontal lines in score plots were considered of importance to PC1 and $\mathrm{PC} 2$, respectively, with $95 \%$ of statistical confidence. This approach allowed to identify the variables (physicochemical parameters, phenolic and volatile compounds) that presented correlation with PC1 and/or PC2.

Classical analyses: color intensity, monomeric anthocyanins and total phenolic compounds

Figure 1a shows the bi-plot that corresponds to the subspace defined by PC1 (43\%) versus PC2 (18\%), obtained by means of ANOVA-PCA approach for the maturation of grapes $(\mathrm{T})$. The distinction between different lengths of maturation occurs mainly throughout $\mathrm{PC} 1$, which means that $\mathrm{PC} 1$ is the main source of data variation and that the effect of maturation is meaningful on physicochemical parameters with respect to experimental error. The longer the period of grape maturation (from $T_{1}, T_{2}$ to $T_{3}$ ), the higher the values of color intensity (e), total monomeric anthocyanins (a, TMA), total phenolic compounds (b, TPC), total polyphenol index (d, TPI), alcohol content (f), and dry extract (h). Letters between brackets are referred to the ones in Table 1, where values of each physicochemical

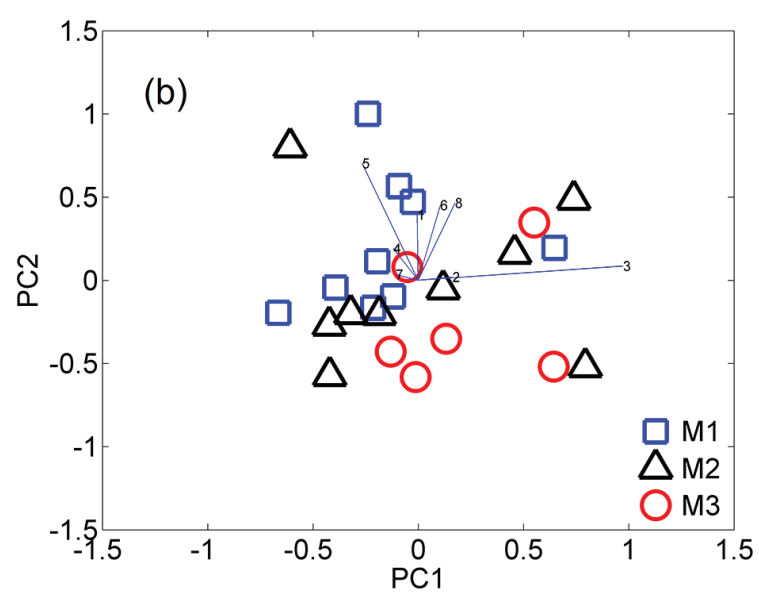

Figure 1. Bi-plot for physicochemical parameters of Syrah wines by means of ANOVA-PCA for (a) different degrees of grape maturation (factor T) and (b) for distinct lengths of maceration (factor $\mathrm{M})$. $\mathrm{T}_{1}$ stands for $113 \mathrm{DAP}\left(19^{\circ} \mathrm{Brix}\right), \mathrm{T}_{2}$ for $120 \mathrm{DAP}\left(21^{\circ} \mathrm{Brix}\right)$, and $\mathrm{T}_{3}$ for $127 \mathrm{DAP}\left(23^{\circ} \mathrm{Brix}\right)$. $\mathrm{M}_{1}$ designates 10 days of maceration; $\mathrm{M}_{2}, 20$; and $\mathrm{M}_{3}, 30$ days. Loadings that exceed the horizontal and vertical dotted lines are statistically significant. 
Table 1. Mean values of several parameters related to Syrah wines elaborated with grapes harvested in different stages of maturation and macerated during distinct periods during the vinification process

\begin{tabular}{|c|c|c|c|c|c|}
\hline \multirow{2}{*}{ Parameter } & \multirow{2}{*}{ Ripeness level } & \multicolumn{3}{|c|}{ Maceration time } & \multirow{2}{*}{$\begin{array}{c}\text { Averages of the } \\
\text { different ripeness level } \\
\left(\mathrm{T}_{1}, \mathrm{~T}_{2} \text { and } \mathrm{T}_{3}\right)^{\mathrm{a}}\end{array}$} \\
\hline & & 10 days $\left(\mathrm{M}_{1}\right)$ & 20 days $\left(\mathrm{M}_{2}\right)$ & 30 days $\left(\mathrm{M}_{3}\right)$ & \\
\hline \multirow{4}{*}{$\begin{array}{l}\text { (a) Total monomeric } \\
\text { anthocyanins (TMA) / } \\
\left(\mathrm{mg} \mathrm{L}^{-1}\right)\end{array}$} & $\mathrm{T}_{1}$ & $145 \pm 10$ & $105 \pm 27$ & & 125 \\
\hline & $\mathrm{T}_{2}$ & $216 \pm 14$ & $198 \pm 15$ & $170 \pm 19$ & 195 \\
\hline & $\mathrm{T}_{3}$ & $233 \pm 29$ & $235 \pm 10$ & $188 \pm 24$ & 219 \\
\hline & $\begin{array}{l}\text { averages of the different } \\
\text { maceration times } \\
\left(\mathrm{M}_{1}, \mathrm{M}_{2} \text { and } \mathrm{M}_{3}\right)^{\mathrm{a}}\end{array}$ & 198 & 179 & 179 & \\
\hline \multirow{4}{*}{$\begin{array}{l}\text { (b) Total phenolic } \\
\text { compounds (TPC) / } \\
\left(\mathrm{mg} \mathrm{L}^{-1}\right)\end{array}$} & $\mathrm{T}_{1}$ & $1375 \pm 216$ & $1441 \pm 140$ & & 1408 \\
\hline & $\mathrm{T}_{2}$ & $1669 \pm 324$ & $1581 \pm 253$ & $1703 \pm 226$ & 1651 \\
\hline & $\mathrm{T}_{3}$ & $2209 \pm 167$ & $2095 \pm 119$ & $2018 \pm 35$ & 2108 \\
\hline & $\begin{array}{l}\text { averages of the different } \\
\text { maceration times } \\
\left(\mathrm{M}_{1}, \mathrm{M}_{2} \text { and } \mathrm{M}_{3}\right)^{\mathrm{a}}\end{array}$ & 1751 & 1706 & 1861 & \\
\hline \multirow{4}{*}{ (c) $\mathrm{pH}$} & $\mathrm{T}_{1}$ & $3.41 \pm 0.09$ & $3.33 \pm 0.04$ & & 3.37 \\
\hline & $\mathrm{T}_{2}$ & $3.29 \pm 0.03$ & $3.36 \pm 0.10$ & $3.41 \pm 0.05$ & 3.35 \\
\hline & $\mathrm{T}_{3}$ & $3.39 \pm 0.02$ & $3.48 \pm 0.11$ & $3.48 \pm 0.11$ & 3.45 \\
\hline & $\begin{array}{l}\text { averages of the different } \\
\text { maceration times } \\
\left(\mathrm{M}_{1}, \mathrm{M}_{2} \text { and } \mathrm{M}_{3}\right)^{\mathrm{a}}\end{array}$ & 3.36 & 3.39 & 3.45 & \\
\hline \multirow{4}{*}{$\begin{array}{l}\text { (d) Total polyphenol } \\
\text { index (TPI) }\end{array}$} & $\mathrm{T}_{1}$ & $41 \pm 2$ & $42 \pm 2$ & & 42 \\
\hline & $\mathrm{T}_{2}$ & $60 \pm 4$ & $62 \pm 5$ & $56 \pm 3$ & 59 \\
\hline & $\mathrm{T}_{3}$ & $66 \pm 2$ & $63 \pm 2$ & $65 \pm 2$ & 65 \\
\hline & $\begin{array}{l}\text { averages of the different } \\
\text { maceration times } \\
\left(\mathrm{M}_{1}, \mathrm{M}_{2} \text { and } \mathrm{M}_{3}\right)^{\mathrm{a}}\end{array}$ & 56 & 56 & 60 & \\
\hline \multirow{4}{*}{$\begin{array}{l}\text { (e) Color intensity } \\
(\mathrm{CI}, 420+520+620 \mathrm{~nm})\end{array}$} & $\mathrm{T}_{1}$ & $10.5 \pm 0.4$ & $9.1 \pm 0.5$ & & 9.8 \\
\hline & $\mathrm{T}_{2}$ & $13.1 \pm 1.9$ & $12.8 \pm 3.3$ & $11.4 \pm 1.6$ & 12.4 \\
\hline & $\mathrm{T}_{3}$ & $13.8 \pm 0.6$ & $13.8 \pm 0.5$ & $13.4 \pm 0.6$ & 13.7 \\
\hline & $\begin{array}{l}\text { averages of the different } \\
\text { maceration times } \\
\left(\mathrm{M}_{1}, \mathrm{M}_{2} \text { and } \mathrm{M}_{3}\right)^{\mathrm{a}}\end{array}$ & 12.5 & 11.9 & 12.4 & \\
\hline \multirow{4}{*}{ (f) Alcohol content / \%v/v } & $\mathrm{T}_{1}$ & $11.5 \pm 0.6$ & $11.5 \pm 0.4$ & & 11.5 \\
\hline & $\mathrm{T}_{2}$ & $14.3 \pm 1.8$ & $14.1 \pm 1.3$ & $13.8 \pm 1.2$ & 14.1 \\
\hline & $\mathrm{T}_{3}$ & $14.6 \pm 0.6$ & $14.6 \pm 0.9$ & $14.6 \pm 0.7$ & 14.6 \\
\hline & $\begin{array}{l}\text { averages of the different } \\
\text { maceration times } \\
\left(\mathrm{M}_{1}, \mathrm{M}_{2} \text { and } \mathrm{M}_{3}\right)^{\mathrm{a}}\end{array}$ & 13.5 & 13.4 & 14.2 & \\
\hline \multirow{4}{*}{$\begin{array}{l}\text { (g) Total titratable acidity } \\
\text { (TA) / }\left(\mathrm{g} \mathrm{L}^{-1}\right)\end{array}$} & $\mathrm{T}_{1}$ & $8.8 \pm 1.6$ & $8.9 \pm 0.9$ & & 8.8 \\
\hline & $\mathrm{T}_{2}$ & $7.9 \pm 0.4$ & $7.3 \pm 0.6$ & $7.7 \pm 0.3$ & 7.6 \\
\hline & $\mathrm{T}_{3}$ & $7.1 \pm 0.2$ & $6.6 \pm 0.4$ & $6.4 \pm 0.04$ & 6.7 \\
\hline & $\begin{array}{l}\text { averages of the different } \\
\text { maceration times } \\
\left(\mathrm{M}_{1}, \mathrm{M}_{2} \text { and } \mathrm{M}_{3}\right)^{\mathrm{a}}\end{array}$ & 7.9 & 7.6 & 7.0 & \\
\hline \multirow{4}{*}{ (h) Dry extract / $\left(\mathrm{g} \mathrm{L}^{-1}\right)$} & $\mathrm{T}_{1}$ & $26 \pm 4$ & $19 \pm 2$ & & 23 \\
\hline & $\mathrm{T}_{2}$ & $27 \pm 3$ & $26 \pm 2$ & $26 \pm 3$ & 26 \\
\hline & $\mathrm{T}_{3}$ & $35 \pm 3$ & $35 \pm 5$ & $34 \pm 1$ & 35 \\
\hline & $\begin{array}{l}\text { averages of the different } \\
\text { maceration times } \\
\left(\mathrm{M}_{1}, \mathrm{M}_{2} \text { and } \mathrm{M}_{3}\right)^{\mathrm{a}}\end{array}$ & 30 & 27 & 30 & \\
\hline
\end{tabular}

${ }^{a}$ Data are expressed as the average values of three-field replicates \pm standard deviation (SD). The result of each treatment (T or M) also comes as the average of triplicate experiments. The number of digits after decimal point was reported according to the lower SD found for a set of specific numbers of one parameter. $\mathrm{T}_{1}: 113$ days after pruning (DAP); $\mathrm{T}_{2}: 120 \mathrm{DAP} ; \mathrm{T}_{3}: 127 \mathrm{DAP}$. 
parameter are listed. Results of triplicate experiments were combined and provided final mean values, as shown in Table 1, in the far right-hand column and in the bottom line. The choice of days after pruning (DAP) for harvesting was based on a previous study of Embrapa ${ }^{28}$ that included several harvest periods and stated 119 DAP as a recommendation for Syrah grape cycle.

Color intensity (e) has shown a pronounced and significant loading on PC1 and was the main parameter for the clustering of $T_{1}, T_{2}$ and $T_{3}$ samples in Figure 1a. This was to be expected, as the presence of colored phenolic compounds increases when grapes are riper. The same trend is followed by TMA, TPC and TPI, as these parameters are all linked to the increase of phenolic compounds. ${ }^{2}$ The range of TPC (b in Table 1) in Syrah wines started with 1408 in $\mathrm{T}_{1}$ and raised to $2108 \mathrm{mg} \mathrm{L}^{-1}$ in $\mathrm{T}_{3}$ and it is in accordance with values formerly reported for Syrah, Pinot Noir, Cabernet (C.) Sauvignon, Malbec, Merlot, among other red wines (948-3526 $\left.\mathrm{mg} \mathrm{L}^{-1}\right){ }^{29} \mathrm{TPI}(\mathrm{d})$ of wines elaborated from grapes from $\mathrm{T}_{1}$ was 42 , while wines made from grapes of a higher degree of maturity (> 120 DAP) reached 65 . These results are in agreement with those reported by Gil et al. ${ }^{30}$ for Tempranillo and C. Sauvignon red wines from Spain (40-68). According to Hernándes, ${ }^{31}$ wines with TPI $\geq 60$ are intended for ageing (wines of guard) and the ones where TPI stays between 45 and 55 are better off as young wines; while wines with TPI $<40$, are considered of low quality. It means that wines elaborated from riper grapes $\left(\mathrm{T}_{3}\right)$ may be directed towards the production of wines of guard, independently of the maceration length.

Alcoholic content (f) of wines was $11.5 \%$ for 113 DAP $\left(\mathrm{T}_{1}\right)$ and $14.6 \%$ for $127 \mathrm{DAP}\left(\mathrm{T}_{3}\right)$ and these values are in line with Brazilian legislation (8.6 to $14 \%) .{ }^{32}$ They are also similar to the range of alcohol content found in Spanish C. Sauvignon and Tempranillo wines, elaborated with grapes of different maturity levels and maceration lengths (11.9-14.6\%). ${ }^{30}$ Finally, the wine dry extract (DE, h) also showed a direct relation with grape maturation, as grapes harvested at $127 \mathrm{DAP}\left(\mathrm{T}_{3}\right)$ provided a higher amount of dry extract. The combination of dry extract, acidity and alcohol provides body and great structure to wine. ${ }^{2}$ It is important to highlight that some variables (phenolic compounds and physicochemical parameters) presented high standard deviations $(>30 \%$ ) because they reflect heterogeneity of grape maturation as a consequence of the lack of uniformity of vineyard management, such as irrigation, nutrition, pruning practices and others, as well as differences that occur in relation to vegetative and productive development of the vines.

Conversely, an antagonistic effect is observed for total titratable acidity (TA, g), as it fell from an average value of 8.83 to $6.69 \mathrm{~g} \mathrm{~L}^{-1}$, when vinification was carried out with grapes harvested $113 \mathrm{DAP}\left(\mathrm{T}_{1}\right)$ and $127 \mathrm{DAP}\left(\mathrm{T}_{3}\right)$, respectively. This decrease in acidity was expected as it is an indicative of grape ripening. ${ }^{2} \mathrm{pH}$ of wines changed accordingly, as it increased (3.37 to 3.45) while TA decreased. Interestingly, variations on $\mathrm{pH}$ (c) that appear in PC2 are not related to the degree of grape maturation factor, but clustering of wines provided by different experiments $\left(\mathrm{T}_{1}, \mathrm{~T}_{2}\right.$ and $\mathrm{T}_{3}$ ) was due to $\mathrm{PC} 1$. The recommended $\mathrm{pH}$ for red wines should be kept in the range of 3.30 to $3.60 .^{33}$

With respect to the length of maceration factor, bi-plot PC1 $\times$ PC 2 shown in Figure 1 b does not reveal the formation of groups according to the maceration times $\left(\mathrm{M}_{1}, \mathrm{M}_{2}\right.$ and $\left.\mathrm{M}_{3}\right)$. This indicates that the experimental error is the main source of variance of the data submitted to ANOVA-PCA and that length of maceration did not have an influence in wine physicochemical parameters. Moreover, the interaction of the degree of grape maturation with the maceration length had no effect in physicochemical parameters, as can be seen in Figure S3a (SI section).

\section{Quantification of phenolic compounds using HPLC-DAD-FD}

Table 2 presents the results of the quantification of phenolic compounds (stilbenes, phenolic acids, flavan3-ols, flavonols, and anthocyanins) and Figure 2 corresponds to a bi-plot obtained after subjecting data regarding concentration of phenolic compounds to ANOVA-PCA. Grape maturation degree showed to be significant for the content of phenolic compounds, as samples appear grouped according to factor levels (Figure 2a) in the space defined by $\mathrm{PC} 1$ versus $\mathrm{PC} 2$, which is consistent with what was observed for the physicochemical parameters.

For most of the phenolic compounds investigated in this work, the increase of the period of grape maturation from $T_{1}$ to $T_{2}$ promotes the enrichment of wine phenolic content. However, the progressive increase in maturation time $\left(T_{2}\right.$ to $\left.T_{3}\right)$ may reduce the concentration of some of these compounds. The influence of maturation is especially remarkable for anthocyanins cyanidin-3-O-glucoside (No. XXIII), delphinidin-3-O-glucoside (No. XXIV), peonidin-3-O-glucoside (No. XXVI), pelargonidin3-O-glucoside (No. XXII), which presented significant PC loadings with respect to the treatment employed. The sum of the concentrations of all anthocyanins were higher in $T_{2}$ and $T_{3}$ wine samples (average of 63 in $T_{1}$ to $95\left(T_{2}\right)$ and $102 \mathrm{mg} \mathrm{L}^{-1}$ in $\mathrm{T}_{3}$, Table 2, Figure 2a), presenting a pattern that was similar to almost all anthocyanins. These concentrations agree with data published for Syrah wines of several traditional wine-production regions (Brazil, Spain, Argentina and Chile), which are in the range 
Table 2. Concentration of phenolic compounds of Syrah wines analyzed with HPLC-DAD-FD and elaborated with grapes coming from different stages of maturation and macerated in distinct periods during vinification

\begin{tabular}{|c|c|c|c|c|c|c|}
\hline \multirow[b]{2}{*}{ No. } & \multirow[b]{2}{*}{ Phenolic compound } & \multirow[b]{2}{*}{ Ripeness level } & \multicolumn{3}{|c|}{ Maceration time } & \multirow{2}{*}{$\begin{array}{c}\text { Average of the } \\
\text { different ripeness } \\
\text { levels } \\
\left(\mathrm{T}_{1}, \mathrm{~T}_{2} \text { and } \mathrm{T}_{3}\right)^{\mathrm{a}}\end{array}$} \\
\hline & & & 10 days $\left(\mathrm{M}_{1}\right)$ & 20 days $\left(\mathrm{M}_{2}\right)$ & 30 days $\left(\mathrm{M}_{3}\right)$ & \\
\hline \multicolumn{7}{|c|}{ Stilbene / (mg L-1) } \\
\hline \multirow{4}{*}{ I } & \multirow{4}{*}{ trans-resveratrol } & $\mathrm{T}_{1}$ & $0.28 \pm 0.03$ & $0.43 \pm 0.19$ & & 0.36 \\
\hline & & $\mathrm{T}_{2}$ & $0.88 \pm 0.08$ & $0.60 \pm 0.10$ & $0.48 \pm 0.10$ & 0.65 \\
\hline & & $\mathrm{T}_{3}$ & $0.60 \pm 0.10$ & $0.43 \pm 0.12$ & $0.60 \pm 0.14$ & 0.54 \\
\hline & & $\begin{array}{l}\text { averages of the different } \\
\text { maceration times } \\
\left(\mathrm{M}_{1}, \mathrm{M}_{2} \text { and } \mathrm{M}_{3}\right)^{\mathrm{a}}\end{array}$ & 0.59 & 0.49 & 0.54 & \\
\hline \multicolumn{7}{|c|}{ Phenolic acid / $\left(\mathrm{mg} \mathrm{L}^{-1}\right)$} \\
\hline \multirow{4}{*}{ II } & \multirow{4}{*}{ gallic acid } & $\mathrm{T}_{1}$ & $9.73 \pm 1.96$ & $14.15 \pm 2.65$ & & 11.94 \\
\hline & & $\mathrm{T}_{2}$ & $10.03 \pm 0.29$ & $14.28 \pm 2.71$ & $18.18 \pm 4.35$ & 14.16 \\
\hline & & $\mathrm{T}_{3}$ & $11.72 \pm 2.63$ & $12.95 \pm 1.31$ & $18.20 \pm 1.20$ & 14.29 \\
\hline & & $\begin{array}{l}\text { averages of the different } \\
\text { maceration times } \\
\left(\mathrm{M}_{1}, \mathrm{M}_{2} \text { and } \mathrm{M}_{3}\right)^{\mathrm{a}}\end{array}$ & 10.49 & 13.79 & 18.19 & \\
\hline \multirow{4}{*}{ III } & \multirow{4}{*}{ caffeic acid } & $\mathrm{T}_{1}$ & $11.80 \pm 1.70$ & $11.23 \pm 1.03$ & & 11.52 \\
\hline & & $\mathrm{T}_{2}$ & $14.50 \pm 0.52$ & $13.97 \pm 0.80$ & $13.63 \pm 4.35$ & 14.03 \\
\hline & & $\mathrm{T}_{3}$ & $14.88 \pm 2.88$ & $11.65 \pm 0.26$ & $13.43 \pm 1.73$ & 13.32 \\
\hline & & $\begin{array}{l}\text { averages of the different } \\
\text { maceration times } \\
\left(\mathrm{M}_{1}, \mathrm{M}_{2} \text { and } \mathrm{M}_{3}\right)^{\mathrm{a}}\end{array}$ & 13.73 & 12.28 & 13.53 & \\
\hline \multirow{4}{*}{ IV } & \multirow{4}{*}{ ferulic acid } & $\mathrm{T}_{1}$ & $1.62 \pm 0.31$ & $1.68 \pm 0.08$ & & 1.65 \\
\hline & & $\mathrm{T}_{2}$ & $2.50 \pm 0.76$ & $2.57 \pm 0.40$ & $2.48 \pm 0.03$ & 2.52 \\
\hline & & $\mathrm{T}_{3}$ & $3.03 \pm 0.60$ & $2.42 \pm 0.03$ & $3.10 \pm 0.42$ & 2.85 \\
\hline & & $\begin{array}{l}\text { averages of the different } \\
\text { maceration times } \\
\left(\mathrm{M}_{1}, \mathrm{M}_{2} \text { and } \mathrm{M}_{3}\right)^{\mathrm{a}}\end{array}$ & 2.38 & 2.22 & 2.79 & \\
\hline \multirow{4}{*}{$\mathrm{V}$} & \multirow{4}{*}{ chlorogenic acid } & $\mathrm{T}_{1}$ & $2.55 \pm 0.39$ & $3.23 \pm 0.43$ & & 2.89 \\
\hline & & $\mathrm{T}_{2}$ & $4.18 \pm 0.95$ & $4.45 \pm 0.09$ & $3.97 \pm 0.29$ & 4.20 \\
\hline & & $\mathrm{T}_{3}$ & $3.97 \pm 0.29$ & $3.08 \pm 0.51$ & $4.35 \pm 0.00$ & 3.80 \\
\hline & & $\begin{array}{l}\text { averages of the different } \\
\text { maceration times } \\
\left(\mathrm{M}_{1}, \mathrm{M}_{2} \text { and } \mathrm{M}_{3}\right)^{\mathrm{a}}\end{array}$ & 3.57 & 3.59 & 4.16 & \\
\hline \multirow{4}{*}{ VI } & \multirow{4}{*}{$p$-coumaric acid } & $\mathrm{T}_{1}$ & $1.17 \pm 0.15$ & $1.10 \pm 0.05$ & & 1.14 \\
\hline & & $\mathrm{T}_{2}$ & $1.85 \pm 0.22$ & $1.58 \pm 0.16$ & $1.55 \pm 0.13$ & 1.66 \\
\hline & & $\mathrm{T}_{3}$ & $1.93 \pm 0.30$ & $1.60 \pm 0.05$ & $2.00 \pm 0.21$ & 1.84 \\
\hline & & $\begin{array}{l}\text { averages of the different } \\
\text { maceration times } \\
\left(\mathrm{M}_{1}, \mathrm{M}_{2} \text { and } \mathrm{M}_{3}\right)^{\mathrm{a}}\end{array}$ & 1.65 & 1.43 & 1.78 & \\
\hline \multirow{4}{*}{ VII } & \multirow{4}{*}{ total phenolic acids } & $\mathrm{T}_{1}$ & $27 \pm 3$ & $31 \pm 3$ & & 29 \\
\hline & & $\mathrm{T}_{2}$ & $33 \pm 3$ & $37 \pm 3$ & $40 \pm 6$ & 37 \\
\hline & & $\mathrm{T}_{3}$ & $36 \pm 7$ & $32 \pm 1$ & $41 \pm 2$ & 36 \\
\hline & & $\begin{array}{l}\text { averages of the different } \\
\text { maceration times } \\
\left(\mathrm{M}_{1}, \mathrm{M}_{2} \text { and } \mathrm{M}_{3}\right)^{\mathrm{a}}\end{array}$ & 32 & 33 & 40 & \\
\hline \multicolumn{7}{|c|}{ Flavan-3-ol / (mg L-1) } \\
\hline \multirow{4}{*}{ VIII } & \multirow{4}{*}{$\begin{array}{l}\text { (-)-epicatechin } \\
\text { gallate }\end{array}$} & $\mathrm{T}_{1}$ & $1.17 \pm 0.38$ & $1.23 \pm 0.24$ & & 1.20 \\
\hline & & $\mathrm{T}_{2}$ & $1.22 \pm 0.38$ & $0.83 \pm 0.25$ & $1.48 \pm 0.24$ & 1.18 \\
\hline & & $\mathrm{T}_{3}$ & $2.10 \pm 0.39$ & $1.75 \pm 0.15$ & $2.40 \pm 0.35$ & 2.08 \\
\hline & & $\begin{array}{l}\text { averages of the different } \\
\text { maceration times } \\
\left(\mathrm{M}_{1}, \mathrm{M}_{2} \text { and } \mathrm{M}_{3}\right)^{\mathrm{a}}\end{array}$ & 1.50 & 1.27 & 1.94 & \\
\hline
\end{tabular}


Table 2. Concentration of phenolic compounds of Syrah wines analyzed with HPLC-DAD-FD and elaborated with grapes coming from different stages of maturation and macerated in distinct periods during vinification (cont.)

\begin{tabular}{|c|c|c|c|c|c|c|}
\hline \multirow[b]{2}{*}{ No. } & \multirow[b]{2}{*}{ Phenolic compound } & \multirow[b]{2}{*}{ Ripeness level } & \multicolumn{3}{|c|}{ Maceration time } & \multirow{2}{*}{$\begin{array}{c}\text { Average of the } \\
\text { different ripenes } \\
\text { levels } \\
\left(\mathrm{T}_{1}, \mathrm{~T}_{2} \text { and } \mathrm{T}_{3}\right)^{\mathrm{a}}\end{array}$} \\
\hline & & & 10 days $\left(\mathbf{M}_{1}\right)$ & 20 days $\left(\mathbf{M}_{2}\right)$ & 30 days $\left(\mathrm{M}_{3}\right)$ & \\
\hline \multirow{6}{*}{ IX } & \multirow{6}{*}{$\begin{array}{l}\text { (-)-epigallocatechin } \\
\text { gallate }\end{array}$} & $\mathrm{T}_{1}$ & $2.17 \pm 0.65$ & $3.05 \pm 0.40$ & & 2.61 \\
\hline & & $\mathrm{T}_{2}$ & $2.32 \pm 0.40$ & $4.67 \pm 1.19$ & $4.73 \pm 1.04$ & 3.91 \\
\hline & & $\mathrm{T}_{3}$ & $3.87 \pm 0.73$ & $3.83 \pm 0.45$ & $5.05 \pm 0.21$ & 4.25 \\
\hline & & averages of the different & & & & \\
\hline & & maceration times & 2.79 & 3.85 & 4.89 & \\
\hline & & $\left(\mathrm{M}_{1}, \mathrm{M}_{2} \text { and } \mathrm{M}_{3}\right)^{\mathrm{a}}$ & & & & \\
\hline \multirow{6}{*}{$\mathrm{X}$} & \multirow{6}{*}{$(+)$-catechin } & $\mathrm{T}_{1}$ & $12.75 \pm 5.56$ & $16.80 \pm 3.86$ & & 14.78 \\
\hline & & $\mathrm{T}_{2}$ & $10.48 \pm 1.82$ & $15.23 \pm 3.59$ & $18.95 \pm 5.24$ & 14.89 \\
\hline & & $\mathrm{T}_{3}$ & $11.90 \pm 2.85$ & $13.28 \pm 1.86$ & $17.85 \pm 0.00$ & 14.34 \\
\hline & & averages of the different & & & & \\
\hline & & maceration times & 11.71 & 15.10 & 18.40 & \\
\hline & & $\left(\mathrm{M}_{1}, \mathrm{M}_{2} \text { and } \mathrm{M}_{3}\right)^{\mathrm{a}}$ & & & & \\
\hline \multirow{6}{*}{ XI } & \multirow{6}{*}{ (-)-epicatechin } & $\mathrm{T}_{1}$ & $5.05 \pm 1.05$ & $7.28 \pm 1.81$ & & 6.17 \\
\hline & & $\mathrm{T}_{2}$ & $4.05 \pm 0.75$ & $6.18 \pm 1.55$ & $8.98 \pm 2.73$ & 6.40 \\
\hline & & $\mathrm{T}_{3}$ & $4.52 \pm 1.37$ & $5.43 \pm 1.08$ & $7.63 \pm 0.46$ & 5.86 \\
\hline & & averages of the different & & & & \\
\hline & & maceration times & 4.54 & 6.30 & 8.31 & \\
\hline & & $\left(\mathrm{M}_{1}, \mathrm{M}_{2} \text { and } \mathrm{M}_{3}\right)^{\mathrm{a}}$ & & & & \\
\hline \multirow{6}{*}{ XII } & \multirow{6}{*}{ procyanidin A2 } & $\mathrm{T}_{1}$ & $1.78 \pm 0.55$ & $1.40 \pm 0.13$ & & 1.59 \\
\hline & & $\mathrm{T}_{2}$ & $1.50 \pm 0.26$ & $3.40 \pm 0.65$ & $3.62 \pm 0.72$ & 2.84 \\
\hline & & $\mathrm{T}_{3}$ & $4.73 \pm 0.90$ & $3.95 \pm 0.31$ & $5.08 \pm 0.25$ & 4.59 \\
\hline & & averages of the different & & & & \\
\hline & & maceration times & 2.67 & 2.92 & 4.35 & \\
\hline & & $\left(\mathrm{M}_{1}, \mathrm{M}_{2} \text { and } \mathrm{M}_{3}\right)^{\mathrm{a}}$ & & & & \\
\hline \multirow{6}{*}{ XIII } & \multirow{6}{*}{ procyanidin B1 } & $\mathrm{T}_{1}$ & $14.07 \pm 2.32$ & $16.68 \pm 1.20$ & & 15.38 \\
\hline & & $\mathrm{T}_{2}$ & $14.05 \pm 1.00$ & $17.47 \pm 2.63$ & $19.15 \pm 4.39$ & 16.87 \\
\hline & & $\mathrm{T}_{3}$ & $15.22 \pm 3.33$ & $13.95 \pm 1.47$ & $17.10 \pm 0.57$ & 15.42 \\
\hline & & averages of the different & & & & \\
\hline & & maceration times & 14.45 & 16.03 & 18.10 & \\
\hline & & $\left(\mathrm{M}_{1}, \mathrm{M}_{2} \text { and } \mathrm{M}_{3}\right)^{\mathrm{a}}$ & & & & \\
\hline \multirow{6}{*}{ XIV } & \multirow{6}{*}{ procyanidin B2 } & $\mathrm{T}_{1}$ & $9.05 \pm 3.10$ & $12.73 \pm 3.60$ & & 10.89 \\
\hline & & $\mathrm{T}_{2}$ & $7.18 \pm 2.01$ & $12.33 \pm 4.27$ & $17.55 \pm 4.82$ & 12.35 \\
\hline & & $\mathrm{T}_{3}$ & $10.08 \pm 2.65$ & $12.70 \pm 2.41$ & $17.40 \pm 0.85$ & 13.39 \\
\hline & & averages of the different & & & & \\
\hline & & maceration times & 8.77 & 12.59 & 17.48 & \\
\hline & & $\left(\mathrm{M}_{1}, \mathrm{M}_{2} \text { and } \mathrm{M}_{3}\right)^{\mathrm{a}}$ & & & & \\
\hline \multirow{6}{*}{ XV } & \multirow{6}{*}{ total flavan-3-ols } & $\mathrm{T}_{1}$ & $46.03 \pm 9.40$ & $59.18 \pm 10.25$ & & 52.50 \\
\hline & & $\mathrm{T}_{2}$ & $40.80 \pm 5.21$ & $60.12 \pm 11.99$ & $74.47 \pm 20.40$ & 58.66 \\
\hline & & $\mathrm{T}_{3}$ & $52.42 \pm 11.34$ & $54.90 \pm 6.46$ & $72.50 \pm 0.07$ & 59.83 \\
\hline & & averages of the different & & & & \\
\hline & & maceration times & 46.42 & 58.07 & 73.49 & \\
\hline & & $\left(\mathrm{M}_{1}, \mathrm{M}_{2} \text { and } \mathrm{M}_{3}\right)^{\mathrm{a}}$ & & & & \\
\hline \multirow{7}{*}{ XVI } & & Flavo & $/\left(\mathrm{mg} \mathrm{L}^{-1}\right)$ & & & \\
\hline & & $\mathrm{T}_{1}$ & $1.27 \pm 0.28$ & $1.30 \pm 0.05$ & & 1.29 \\
\hline & & $\mathrm{T}_{2}$ & $1.97 \pm 0.29$ & $1.65 \pm 0.30$ & $1.63 \pm 0.56$ & 1.75 \\
\hline & kaempferol- & $\mathrm{T}_{3}$ & $1.08 \pm 0.09$ & $1.40 \pm 0.43$ & $2.00 \pm 0.42$ & 1.49 \\
\hline & 3-O-glucoside & averages of the different & & & & \\
\hline & & maceration times & 1.44 & 1.45 & 1.82 & \\
\hline & & $\left(\mathrm{M}_{1}, \mathrm{M}_{2} \text { and } \mathrm{M}_{3}\right)^{\mathrm{a}}$ & & & & \\
\hline
\end{tabular}


Table 2. Concentration of phenolic compounds of Syrah wines analyzed with HPLC-DAD-FD and elaborated with grapes coming from different stages of maturation and macerated in distinct periods during vinification (cont.)

\begin{tabular}{|c|c|c|c|c|c|c|}
\hline \multirow[b]{2}{*}{ No. } & \multirow[b]{2}{*}{ Phenolic compound } & \multirow[b]{2}{*}{ Ripeness level } & \multicolumn{3}{|c|}{ Maceration time } & \multirow{2}{*}{$\begin{array}{c}\text { Average of the } \\
\text { different ripeness } \\
\text { levels } \\
\left(\mathrm{T}_{1}, \mathrm{~T}_{2} \text { and } \mathrm{T}_{3}\right)^{\mathrm{a}}\end{array}$} \\
\hline & & & 10 days $\left(\mathrm{M}_{1}\right)$ & 20 days $\left(\mathrm{M}_{2}\right)$ & 30 days $\left(\mathrm{M}_{3}\right)$ & \\
\hline \multirow{6}{*}{ XVII } & \multirow{6}{*}{$\begin{array}{l}\text { isorhamnetin- } \\
\text { 3-O-glucoside }\end{array}$} & $\mathrm{T}_{1}$ & $6.03 \pm 1.76$ & $6.02 \pm 1.81$ & & 6.03 \\
\hline & & $\mathrm{T}_{2}$ & $11.30 \pm 4.30$ & $11.12 \pm 3.82$ & $10.03 \pm 1.67$ & 10.82 \\
\hline & & $\mathrm{T}_{3}$ & $11.53 \pm 3.01$ & $9.88 \pm 1.36$ & $12.25 \pm 0.00$ & 11.22 \\
\hline & & averages of the different & & & & \\
\hline & & maceration times & 9.62 & 9.01 & 11.14 & \\
\hline & & $\left(\mathrm{M}_{1}, \mathrm{M}_{2} \text { and } \mathrm{M}_{3}\right)^{\mathrm{a}}$ & & & & \\
\hline \multirow{6}{*}{ XVIII } & \multirow{6}{*}{ myricetin } & $\mathrm{T}_{1}$ & $0.42 \pm 0.13$ & $0.15 \pm 0.05$ & & 0.29 \\
\hline & & $\mathrm{T}_{2}$ & $0.32 \pm 0.13$ & $0.88 \pm 0.25$ & $0.80 \pm 0.05$ & 0.67 \\
\hline & & $\mathrm{T}_{3}$ & $0.75 \pm 0.15$ & $0.60 \pm 0.05$ & $1.00 \pm 0.00$ & 0.78 \\
\hline & & averages of the different & & & & \\
\hline & & maceration times & 0.50 & 0.54 & 0.90 & \\
\hline & & $\left(\mathrm{M}_{1}, \mathrm{M}_{2} \text { and } \mathrm{M}_{3}\right)^{\mathrm{a}}$ & & & & \\
\hline \multirow{6}{*}{ XIX } & \multirow{6}{*}{ quercetin } & $\mathrm{T}_{1}$ & $0.25 \pm 0.09$ & $0.28 \pm 0.88$ & & 0.27 \\
\hline & & $\mathrm{T}_{2}$ & $0.52 \pm 0.03$ & $0.50 \pm 0.00$ & $0.53 \pm 0.15$ & 0.52 \\
\hline & & $\mathrm{T}_{3}$ & $0.40 \pm 0.10$ & $0.30 \pm 0.10$ & $0.63 \pm 0.11$ & 0.44 \\
\hline & & averages of the different & & & & \\
\hline & & maceration times & 0.39 & 0.36 & 0.58 & \\
\hline & & $\left(\mathrm{M}_{1}, \mathrm{M}_{2} \text { and } \mathrm{M}_{3}\right)^{\mathrm{a}}$ & & & & \\
\hline \multirow{6}{*}{$\mathrm{XX}$} & \multirow{6}{*}{ rutin } & $\mathrm{T}_{1}$ & $0.77 \pm 0.15$ & $0.73 \pm 0.06$ & & 0.75 \\
\hline & & $\mathrm{T}_{2}$ & $1.30 \pm 0.23$ & $0.75 \pm 0.15$ & $0.75 \pm 0.13$ & 0.93 \\
\hline & & $\mathrm{T}_{3}$ & $0.98 \pm 0.20$ & $0.77 \pm 0.03$ & $1.00 \pm 0.14$ & 0.92 \\
\hline & & averages of the different & & & & \\
\hline & & maceration times & 1.02 & 0.75 & 0.88 & \\
\hline & & $\left(\mathrm{M}_{1}, \mathrm{M}_{2} \text { and } \mathrm{M}_{3}\right)^{\mathrm{a}}$ & & & & \\
\hline \multirow{6}{*}{ XXI } & \multirow{6}{*}{ total flavonols } & $\mathrm{T}_{1}$ & $9.73 \pm 3.00$ & $8.48 \pm 1.77$ & & 8.61 \\
\hline & & $\mathrm{T}_{2}$ & $15.40 \pm 4.97$ & $14.90 \pm 4.75$ & $13.75 \pm 2.38$ & 14.68 \\
\hline & & $\mathrm{T}_{3}$ & $14.75 \pm 3.99$ & $12.95 \pm 1.66$ & $16.88 \pm 0.46$ & 14.86 \\
\hline & & averages of the different & & & & \\
\hline & & maceration times & 12.96 & 12.11 & 15.32 & \\
\hline & & $\left(\mathrm{M}_{1}, \mathrm{M}_{2} \text { and } \mathrm{M}_{3}\right)^{\mathrm{a}}$ & & & & \\
\hline \multicolumn{7}{|c|}{ Anthocyanin / $\left(\mathrm{mg} \mathrm{L}^{-1}\right)$} \\
\hline \multirow{6}{*}{ XXII } & \multirow{6}{*}{$\begin{array}{l}\text { pelargonidin- } \\
\text { 3-O-glucoside }\end{array}$} & $\mathrm{T}_{1}$ & $8.17 \pm 0.53$ & $8.08 \pm 1.71$ & & 8.13 \\
\hline & & $\mathrm{T}_{2}$ & $12.70 \pm 0.85$ & $10.87 \pm 0.83$ & $9.95 \pm 1.23$ & 11.17 \\
\hline & & $\mathrm{T}_{3}$ & $12.55 \pm 2.34$ & $9.68 \pm 1.26$ & $11.53 \pm 0.67$ & 11.25 \\
\hline & & averages of the different & & & & \\
\hline & & maceration times & 11.14 & 9.54 & 10.74 & \\
\hline & & $\left(\mathrm{M}_{1}, \mathrm{M}_{2} \text { and } \mathrm{M}_{3}\right)^{\mathrm{a}}$ & & & & \\
\hline \multirow{6}{*}{ XXIII } & \multirow{6}{*}{$\begin{array}{c}\text { cyanidin- } \\
\text { 3-O-glucoside }\end{array}$} & $\mathrm{T}_{1}$ & $0.45 \pm 0.13$ & $0.48 \pm 0.20$ & & 0.47 \\
\hline & & $\mathrm{T}_{2}$ & $0.72 \pm 0.10$ & $0.65 \pm 0.09$ & $0.55 \pm 0.13$ & 0.64 \\
\hline & & $\mathrm{T}_{3}$ & $0.53 \pm 0.14$ & $0.40 \pm 0.10$ & $0.43 \pm 0.04$ & 0.45 \\
\hline & & averages of the different & & & & \\
\hline & & maceration times & 0.57 & 0.51 & 0.49 & \\
\hline & & $\left(\mathrm{M}_{1}, \mathrm{M}_{2} \text { and } \mathrm{M}_{3}\right)^{\mathrm{a}}$ & & & & \\
\hline & & $\mathrm{T}_{1}$ & $3.40 \pm 0.35$ & $3.42 \pm 0.90$ & & 3.41 \\
\hline & & $\mathrm{T}_{2}$ & $4.87 \pm 0.48$ & $3.98 \pm 0.10$ & $3.67 \pm 0.64$ & 4.17 \\
\hline XXIV & delphinidin- & $\mathrm{T}_{3}$ & $4.27 \pm 0.90$ & $3.32 \pm 0.63$ & $3.73 \pm 0.04$ & 3.77 \\
\hline XXIV & 3-O-glucoside & averages of the different & & & & \\
\hline & & maceration times & 4.18 & 3.57 & 3.70 & \\
\hline & & $\left(\mathrm{M}_{1}, \mathrm{M}_{2} \text { and } \mathrm{M}_{3}\right)^{\mathrm{a}}$ & & & & \\
\hline
\end{tabular}


Table 2. Concentration of phenolic compounds of Syrah wines analyzed with HPLC-DAD-FD and elaborated with grapes coming from different stages of maturation and macerated in distinct periods during vinification (cont.)

\begin{tabular}{|c|c|c|c|c|c|c|}
\hline \multirow[b]{2}{*}{ No. } & \multirow[b]{2}{*}{ Phenolic compound } & \multirow[b]{2}{*}{ Ripeness level } & \multicolumn{3}{|c|}{ Maceration time } & \multirow{2}{*}{$\begin{array}{c}\text { Average of the } \\
\text { different ripeness } \\
\text { levels } \\
\left(\mathrm{T}_{1}, \mathrm{~T}_{2} \text { and } \mathrm{T}_{3}\right)^{\mathrm{a}}\end{array}$} \\
\hline & & & 10 days $\left(\mathrm{M}_{1}\right)$ & 20 days $\left(\mathrm{M}_{2}\right)$ & 30 days $\left(\mathrm{M}_{3}\right)$ & \\
\hline \multirow{4}{*}{ XXV } & \multirow{4}{*}{$\begin{array}{l}\text { malvidin-3-O- } \\
\text { glucoside }\end{array}$} & $\mathrm{T}_{1}$ & $47 \pm 8$ & $47 \pm 1$ & & 47 \\
\hline & & $\mathrm{T}_{2}$ & $79 \pm 9$ & $72 \pm 8$ & $69 \pm 7$ & 73 \\
\hline & & $\mathrm{T}_{3}$ & $86 \pm 15$ & $70 \pm 1$ & $86 \pm 10$ & 81 \\
\hline & & $\begin{array}{l}\text { averages of the different } \\
\text { maceration times } \\
\left(\mathrm{M}_{1}, \mathrm{M}_{2} \text { and } \mathrm{M}_{3}\right)^{\mathrm{a}}\end{array}$ & 70 & 63 & 78 & \\
\hline \multirow{4}{*}{ XXVI } & \multirow{4}{*}{$\begin{array}{l}\text { peonidin-3-O- } \\
\text { glucoside }\end{array}$} & $\mathrm{T}_{1}$ & $4.13 \pm 0.32$ & $4.27 \pm 0.94$ & & 4.20 \\
\hline & & $\mathrm{T}_{2}$ & $6.70 \pm 0.52$ & $5.83 \pm 0.30$ & $5.45 \pm 1.03$ & 5.99 \\
\hline & & $\mathrm{T}_{3}$ & $6.07 \pm 1.16$ & $4.93 \pm 0.53$ & $5.53 \pm 0.04$ & 5.51 \\
\hline & & $\begin{array}{l}\text { averages of the different } \\
\text { maceration times } \\
\left(\mathrm{M}_{1}, \mathrm{M}_{2} \text { and } \mathrm{M}_{3}\right)^{\mathrm{a}}\end{array}$ & 5.63 & 5.01 & 5.49 & \\
\hline \multirow{4}{*}{ XXVII } & \multirow{4}{*}{ total anthocyanins } & $\mathrm{T}_{1}$ & $63 \pm 8$ & $63 \pm 4$ & & 63 \\
\hline & & $\mathrm{T}_{2}$ & $104 \pm 9$ & $93 \pm 8$ & $88 \pm 9$ & 95 \\
\hline & & $\mathrm{T}_{3}$ & $109 \pm 19$ & $89 \pm 4$ & $107 \pm 10$ & 102 \\
\hline & & $\begin{array}{l}\text { averages of the different } \\
\text { maceration times } \\
\left(\mathrm{M}_{1}, \mathrm{M}_{2} \text { and } \mathrm{M}_{3}\right)^{\mathrm{a}}\end{array}$ & 92 & 82 & 98 & \\
\hline
\end{tabular}

${ }^{a}$ Data are expressed as the average values of three-field replicates \pm standard deviation (SD). The result of each treatment (T or M) also comes as the average of triplicate experiments. The number of digits after decimal point was reported according to the lower SD found for a set of specific numbers of one parameter. All compounds were included in ANOVA-PCA, except for the sum of concentrations of each subclass of compounds. $\mathrm{T}_{1}: 113$ days after pruning (DAP); $\mathrm{T}_{2}: 120 \mathrm{DAP} ; \mathrm{T}_{3}: 127 \mathrm{DAP}$.
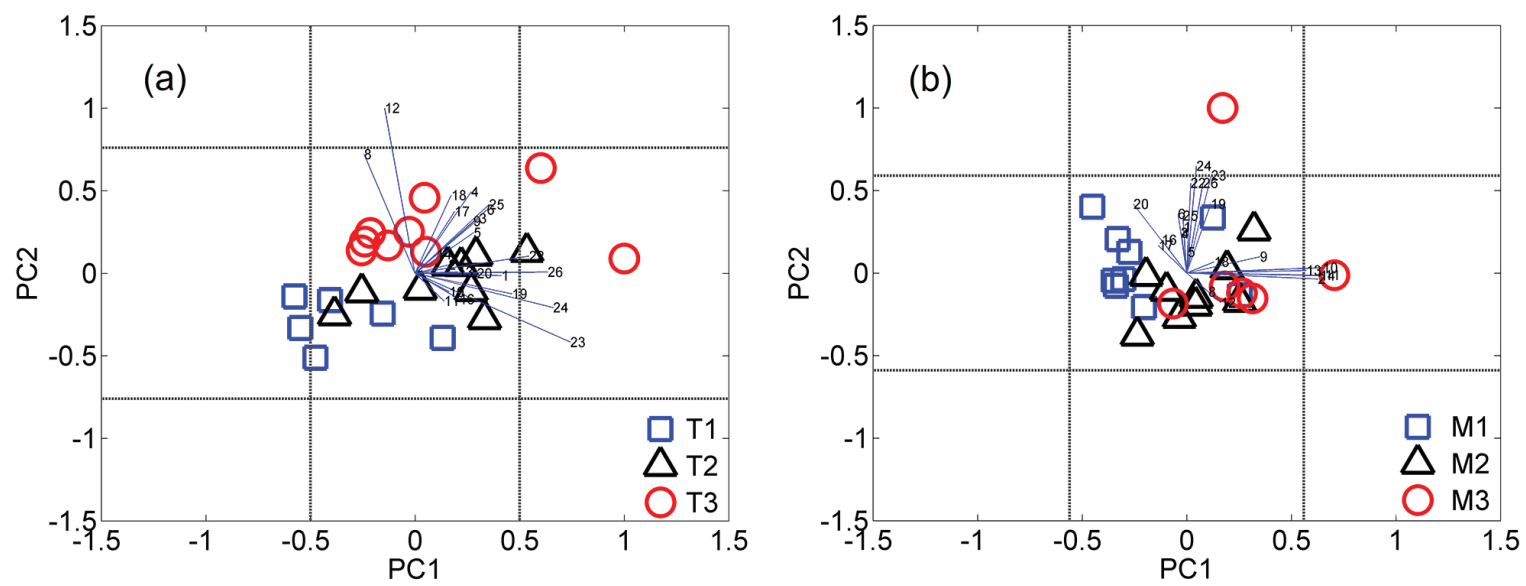

Figure 2. (a) Bi-plot $(\mathrm{PC} 1=25 \%$ and $\mathrm{PC} 2=16 \%)$ for phenolic compounds of Syrah wines by means of ANOVA-PCA for different degrees of grape maturation (factor $\mathrm{T})$ and $(\mathrm{b})(\mathrm{PC} 1=25 \%$ and $\mathrm{PC} 2=16 \%$ ) for distinct lengths of maceration (factor $\mathrm{M})$. $\mathrm{T}_{1}$ stands for $113 \mathrm{DAP}\left(19{ }^{\circ} \mathrm{Brix}\right)$, $\mathrm{T}_{2}$ for $120 \mathrm{DAP}\left(21^{\circ} \mathrm{Brix}\right)$, and $\mathrm{T}_{3}$ for $127 \mathrm{DAP}\left(23^{\circ} \mathrm{Brix}\right)$. $\mathrm{M}_{1}$ designates 10 days of maceration; $\mathrm{M}_{2}, 20$; and $\mathrm{M}_{3}, 30$ days. Loadings that exceed the horizontal and vertical dotted lines are statistically significant.

of 11.89 to $259.59 \mathrm{mg} \mathrm{L}^{-1} .{ }^{29,34}$ The evolution of these anthocyanins (except for No. XXII) during grape ripening was investigated in Nebbiolo grapes from Italy, and their content also increased from 31.34 to $272.17 \mathrm{mg} \mathrm{kg}^{-1}$ when their soluble solids increased from 22.6 to $25.0{ }^{\circ}$ Brix. Phenolic acids (29.14 in $\mathrm{T}_{1}$ to $36.10 \mathrm{mg} \mathrm{L}^{-1}$ in $\mathrm{T}_{3}$ ) followed similar trend, which is also in accordance with the raise in $p$-coumaric acid concentration from 0.03 to $0.06 \mathrm{mg} \mathrm{kg}^{-1}$ detected in the same Nebbiolo grapes. ${ }^{7}$ Phenolic acids are reported as having no particular influence in the wine taste or odor, even though, they are precursors of volatile phenols produced by the action of yeasts of the genus Brettanomyces. Ethyl phenols are examples of these phenols, known to impart an "animal" odor note to red wines. ${ }^{2}$ Likewise, the total concentration of flavonols showed a growth when wine was made with riper grapes, 
ranging from $8.61 \mathrm{~T}_{1}$ to $14.86 \mathrm{mg} \mathrm{L}^{-1}$ in $\mathrm{T}_{3}$. In a like manner, flavonols myricetin (No. XVIII) and quercetin (No. XIX) in riper Tannat grape skins, reached higher concentrations. ${ }^{35}$ Interestingly, the flavan-3-ol procyanidin A2 (No. XII) showed a significant loading along PC2, as its content increased with a prolonged grape maturation. It may be further investigated as a target chemical to provide information about the progress of maturation process.

Figure $2 b$ displays a bi-plot for the effect of maceration (factor $\mathrm{M}$ ) on the phenolic content of samples, where $M_{1}$ and $M_{2}$ wine samples were preferably grouped on opposite sides of the bisector dividing the subspace defined by PC1 versus PC2. Samples submitted to 30 days of maceration $\left(\mathrm{M}_{3}\right)$ are shown as scattered points without an apparent pattern, which suggests that the $\mathrm{M}$ factor level changing from $M_{2}$ to $M_{3}$ did not affect significantly the concentration of phenolic compound. The two sets of more expressive loadings are oriented preferentially along PC1 and PC2, pointing to two unrelated events of the effect of maceration on wine concentration of phenolic compounds. Concentrations of anthocyanins delphinidin-3-O-glucoside (No. XXIV, PC2 0.6478), cyanidin-3-O-glucoside (No. XXIII, PC2 0.5907) were reduced as maceration length was extended from $M_{1}$ to $M_{3}$. The evolution of the concentration of several individual anthocyanins (Table 2) is in accordance with a study reported about Teran wines from Croatia, ${ }^{36}$ where the effect of maceration times $(5,10$, 15 and 20 days) was investigated for the same anthocyanins and their content increased to a maximum within 10 days of maceration. These compounds are the main responsible for the color in grapes and wines, contributing positively to their quality, since they influence the sensorial characteristics and the acceptability of the wine by the consumer. ${ }^{34}$ Conversely, flavan-3-ols (-)-epicatechin (No. XI), (+)-catechin (No. X), procyanidin B2 (No. XIV), procyanidin B1 (No. XIII), and gallic acid (No. II) showed higher loadings in PC1, as their concentrations increased with longer maceration. The total sum of flava-3-ols followed the same path of the individual flavan-3-ol Nos. X, XI, XIII, and XIV, increasing with longer maceration periods. A study about the concentrations of (+)-catechin (No. X) and (-)-epicatechin (No. XI) in Spanish Syrah wines has also achieved higher concentrations in wines macerated during 10 days than in the wines macerated for 5 days (from 9.8 to $17.8 \mathrm{mg} \mathrm{L}^{-1}$ to No. $\mathrm{X}$ and from 5.2 to $15.0 \mathrm{mg} \mathrm{L}^{-1}$ to No. XI). ${ }^{37}$ Similar pattern has been observed for both flavan-3-ols in Karaoglan red wines from Turkey ${ }^{8}$ and Teran red wines from Croatia. ${ }^{36}$ The extraction of flavan3-ols from the grape skin starts in the first two or three days of maceration due to their high water solubility, although the release of flavan-3-ols from the seeds requires longer maceration times. These compounds are usually related to wine properties, including astringency and bitterness. ${ }^{38}$

Gallic acid (No. II) was the major phenolic acid of Syrah wines, ranging from 9.73 in $\mathrm{T}_{1} \mathrm{M}_{1}$ to $18.20 \mathrm{mg} \mathrm{L}^{-1}$ in $\mathrm{T}_{3} \mathrm{M}_{3}$. Other researchers have also found it as the major phenolic acid in red wines of other countries, such as France and Italy ${ }^{29}$ Accordingly, red Croatian Teran wine presented $9.15 \mathrm{mg} \mathrm{L}^{-1}$ of gallic acid, after five days of maceration, which increased to $11.89 \mathrm{mg} \mathrm{L}^{-1}$, after a 20-day maceration. ${ }^{36}$ During the maceration and fermentation processes, gallic acid is extracted from the seeds after the hydrolysis of the gallate esters of the flavonols, under the action of esterases, and its esterification with ethanol to form ethyl gallate also appears to occur during fermentation and ageing conditions. ${ }^{34}$ Eventually, no significant effect was observed on phenolic compounds due to interaction of grape maturation degree with maceration time, as can be seen in Figure S3b (SI section).

\section{Syrah wine volatile profile}

Headspace solid phase microextraction with gas chromatography/mass spectrometry method validation

The performance of the chromatographic method was evaluated in terms of linearity, limits of detection (LOD) and quantification (LOQ), precision (repeatability and intermediate precision) and accuracy and data is shown in Table S3 (SI section). The range of concentration for each volatile compound was chosen according to previously published papers ${ }^{24}$ and to preliminary analyses carried out to confirm the corresponding ranges of linearity. Eleven calibration curves (Table S3, SI section) were employed to quantify the 41 volatile compounds (12 esters, 10 acids, 14 alcohols, 4 terpenes, and one thiol) (Table 3), out of the 52 tentatively identified compounds. Table S2 (SI section) shows data related to the identification of the 41 quantified compounds, as well as to eleven components designated with Roman numbers, which were not quantified. Their calculated OAV and published odor threshold concentrations are also reported. Arabic numbers were used to designate the 41 quantified volatiles, as well as the sum of concentrations of four subclasses of compounds (acids, alcohols, esters, and terpenes).

The calibration curves showed good linearity with determination coefficients ranging from 0.990 to 0.999 . The values of LOD ranged from $3.6 \mu \mathrm{g} \mathrm{L}^{-1}$ for linalool to $363.3 \mu \mathrm{g} \mathrm{L}^{-1}$ for 2-phenyl ethanol. LOQ ranged from $11.0 \mu \mathrm{g} \mathrm{L}-1$ for linalool to $1101.8 \mu \mathrm{g} \mathrm{L} \mathrm{L}^{-1}$ for 2-phenyl ethanol. Repeatability ranged from $1.2 \%$ for ethyl hexanoate to $16.7 \%$ for ethyl decanoate. Intermediate precision ranged 
Table 3. Concentration of volatile compounds of Syrah wines analyzed with GC-MS and elaborated with grapes coming from different stages of maturation and macerated in distinct periods during vinification

\begin{tabular}{|c|c|c|c|c|c|c|}
\hline \multirow[b]{2}{*}{ No. } & \multirow[b]{2}{*}{ Volatile compound } & \multirow[b]{2}{*}{ Ripeness level } & \multicolumn{3}{|c|}{ Maceration time } & \multirow{2}{*}{$\begin{array}{c}\text { Averages of the } \\
\text { different ripeness } \\
\text { levels } \\
\left(\mathrm{T}_{1}, \mathrm{~T}_{2} \text { and } \mathrm{T}_{3}\right)^{\mathrm{a}}\end{array}$} \\
\hline & & & 10 days $\left(\mathrm{M}_{1}\right)$ & 20 days $\left(\mathrm{M}_{2}\right)$ & 30 days $\left(\mathrm{M}_{3}\right)$ & \\
\hline \multicolumn{7}{|c|}{ Ester / $\left(\mu \mathrm{g} \mathrm{L}^{-1}\right)$} \\
\hline \multirow{4}{*}{1} & \multirow{4}{*}{$\begin{array}{l}\text { 3-methylbutyl } \\
\text { acetate }\end{array}$} & $\mathrm{T}_{1}$ & $922 \pm 7$ & $433 \pm 44$ & & 678 \\
\hline & & $\mathrm{T}_{2}$ & $763 \pm 86$ & $1022 \pm 105$ & $463 \pm 55$ & 749 \\
\hline & & $\mathrm{T}_{3}$ & $1451 \pm 111$ & $561 \pm 17$ & $263 \pm 59$ & 758 \\
\hline & & $\begin{array}{l}\text { averages of the different maceration } \\
\text { times }\left(\mathrm{M}_{1}, \mathrm{M}_{2} \text { and } \mathrm{M}_{3}\right)^{\mathrm{a}}\end{array}$ & 1045 & 672 & 363 & \\
\hline \multirow{4}{*}{2} & \multirow{4}{*}{ ethyl butanoate } & $\mathrm{T}_{1}$ & $75 \pm 12$ & $76 \pm 16$ & & 76 \\
\hline & & $\mathrm{T}_{2}$ & $136 \pm 20$ & $320 \pm 4$ & $297 \pm 92$ & 251 \\
\hline & & $\mathrm{T}_{3}$ & $198 \pm 38$ & $486 \pm 107$ & $501 \pm 5$ & 395 \\
\hline & & $\begin{array}{l}\text { averages of the different maceration } \\
\text { times }\left(\mathrm{M}_{1}, \mathrm{M}_{2} \text { and } \mathrm{M}_{3}\right)^{\mathrm{a}}\end{array}$ & 136 & 294 & 399 & \\
\hline \multirow{4}{*}{3} & \multirow{4}{*}{ ethyl hexanoate } & $\mathrm{T}_{1}$ & $786 \pm 1$ & $537 \pm 25$ & & 662 \\
\hline & & $\mathrm{T}_{2}$ & $271 \pm 28$ & $421 \pm 29$ & $182 \pm 10$ & 291 \\
\hline & & $\mathrm{T}_{3}$ & $243 \pm 10$ & $212 \pm 36$ & $229 \pm 37$ & 228 \\
\hline & & $\begin{array}{l}\text { averages of the different maceration } \\
\text { times }\left(\mathrm{M}_{1}, \mathrm{M}_{2} \text { and } \mathrm{M}_{3}\right)^{\mathrm{a}}\end{array}$ & 433 & 390 & 206 & \\
\hline \multirow{4}{*}{4} & \multirow{4}{*}{ ethyl lactate } & $\mathrm{T}_{1}$ & $395 \pm 2$ & $425 \pm 23$ & & 410 \\
\hline & & $\mathrm{T}_{2}$ & $1348 \pm 173$ & $1983 \pm 63$ & $2957 \pm 68$ & 2096 \\
\hline & & $\mathrm{T}_{3}$ & $457 \pm 12$ & $1471 \pm 115$ & $1370 \pm 28$ & 1099 \\
\hline & & $\begin{array}{l}\text { averages of the different maceration } \\
\text { times }\left(\mathrm{M}_{1}, \mathrm{M}_{2} \text { and } \mathrm{M}_{3}\right)^{\mathrm{a}}\end{array}$ & 733 & 1293 & 2164 & \\
\hline \multirow{4}{*}{5} & \multirow{4}{*}{ ethyl octanoate } & $\mathrm{T}_{1}$ & $2342 \pm 54$ & $1789 \pm 36$ & & 2066 \\
\hline & & $\mathrm{T}_{2}$ & $1121 \pm 35$ & $1252 \pm 74$ & $955 \pm 34$ & 1109 \\
\hline & & $\mathrm{T}_{3}$ & $1133 \pm 61$ & $1006 \pm 22$ & $945 \pm 82$ & 1028 \\
\hline & & $\begin{array}{l}\text { averages of the different maceration } \\
\text { times }\left(\mathrm{M}_{1}, \mathrm{M}_{2} \text { and } \mathrm{M}_{3}\right)^{\mathrm{a}}\end{array}$ & 1532 & 1349 & 950 & \\
\hline \multirow{4}{*}{6} & \multirow{4}{*}{ ethyl decanoate } & $\mathrm{T}_{1}$ & $171 \pm 28$ & $107 \pm 11$ & & 139 \\
\hline & & $\mathrm{T}_{2}$ & $134 \pm 14$ & $88 \pm 21$ & $91 \pm 23$ & 104 \\
\hline & & $\mathrm{T}_{3}$ & $131 \pm 24$ & $107 \pm 21$ & $122 \pm 12$ & 120 \\
\hline & & $\begin{array}{l}\text { averages of the different maceration } \\
\text { times }\left(\mathrm{M}_{1}, \mathrm{M}_{2} \text { and } \mathrm{M}_{3}\right)^{\mathrm{a}}\end{array}$ & 145 & 101 & 107 & \\
\hline \multirow{4}{*}{7} & \multirow{4}{*}{$\begin{array}{l}\text { 3-methylbutyl } \\
\text { octanoate }\end{array}$} & $\mathrm{T}_{1}$ & $44 \pm 1$ & $17 \pm 3$ & & 31 \\
\hline & & $\mathrm{T}_{2}$ & $10 \pm 1$ & $13 \pm 2$ & $10 \pm 1$ & 11 \\
\hline & & $\mathrm{T}_{3}$ & $11 \pm 1$ & $10 \pm 0$ & $22 \pm 1$ & 14 \\
\hline & & $\begin{array}{l}\text { averages of the different maceration } \\
\text { times }\left(\mathrm{M}_{1}, \mathrm{M}_{2} \text { and } \mathrm{M}_{3}\right)^{\mathrm{a}}\end{array}$ & 22 & 13 & 16 & \\
\hline \multirow{4}{*}{8} & \multirow{4}{*}{$\begin{array}{c}\text { diethyl } \\
\text { butanedioate }\end{array}$} & $\mathrm{T}_{1}$ & $865 \pm 53$ & $1219 \pm 125$ & & 1042 \\
\hline & & $\mathrm{T}_{2}$ & $3322 \pm 228$ & $2802 \pm 286$ & $2978 \pm 283$ & 3034 \\
\hline & & $\mathrm{T}_{3}$ & $939 \pm 38$ & $2485 \pm 6$ & $7588 \pm 336$ & 3671 \\
\hline & & $\begin{array}{l}\text { averages of the different maceration } \\
\text { times }\left(\mathrm{M}_{1}, \mathrm{M}_{2} \text { and } \mathrm{M}_{3}\right)^{\mathrm{a}}\end{array}$ & 1709 & 2169 & 5283 & \\
\hline \multirow{4}{*}{9} & \multirow{4}{*}{$\begin{array}{c}\text { ethyl } \\
\text { 2-phenylacetate }\end{array}$} & $\mathrm{T}_{1}$ & $211 \pm 41$ & $66 \pm 9$ & & 139 \\
\hline & & $\mathrm{T}_{2}$ & $69 \pm 2$ & $80 \pm 3$ & $89 \pm 9$ & 79 \\
\hline & & $\mathrm{T}_{3}$ & $59 \pm 2$ & $70 \pm 9$ & $77 \pm 13$ & 69 \\
\hline & & $\begin{array}{l}\text { averages of the different maceration } \\
\text { times }\left(\mathrm{M}_{1}, \mathrm{M}_{2} \text { and } \mathrm{M}_{3}\right)^{\mathrm{a}}\end{array}$ & 113 & 72 & 83 & \\
\hline & & $\mathrm{T}_{1}$ & $43 \pm 1$ & $6 \pm 0$ & & 25 \\
\hline & & $\mathrm{T}_{2}$ & $11 \pm 2$ & $7 \pm 2$ & $14 \pm 1$ & 11 \\
\hline 10 & ethyl 9-decenoate & $\mathrm{T}_{3}$ & $48 \pm 4$ & $25 \pm 1$ & $42 \pm 1$ & 38 \\
\hline & & $\begin{array}{l}\text { averages of the different maceration } \\
\text { times }\left(\mathrm{M}_{1}, \mathrm{M}_{2} \text { and } \mathrm{M}_{3}\right)^{\mathrm{a}}\end{array}$ & 34 & 13 & 28 & \\
\hline
\end{tabular}


Table 3. Concentration of volatile compounds of Syrah wines analyzed with GC-MS and elaborated with grapes coming from different stages of maturation and macerated in distinct periods during vinification (cont.)

\begin{tabular}{|c|c|c|c|c|c|c|}
\hline \multirow[b]{2}{*}{ No. } & \multirow[b]{2}{*}{ Volatile compound } & \multirow[b]{2}{*}{ Ripeness level } & \multicolumn{3}{|c|}{ Maceration time } & \multirow{2}{*}{$\begin{array}{c}\text { Averages of the } \\
\text { different ripeness } \\
\text { levels } \\
\left(\mathrm{T}_{1}, \mathrm{~T}_{2} \text { and } \mathrm{T}_{3}\right)^{\mathrm{a}}\end{array}$} \\
\hline & & & 10 days $\left(\mathrm{M}_{1}\right)$ & 20 days $\left(\mathrm{M}_{2}\right)$ & 30 days $\left(\mathrm{M}_{3}\right)$ & \\
\hline \multirow{4}{*}{11} & \multirow{4}{*}{$\begin{array}{l}\text { ethyl } \\
\text { tetradecanoate }\end{array}$} & $\mathrm{T}_{1}$ & $13 \pm 2$ & $25 \pm 2$ & & 19 \\
\hline & & $\mathrm{T}_{2}$ & $17 \pm 1$ & $12 \pm 1$ & $9 \pm 1$ & 13 \\
\hline & & $\mathrm{T}_{3}$ & $10 \pm 1$ & $211 \pm 1$ & $531 \pm 1$ & 251 \\
\hline & & $\begin{array}{l}\text { averages of the different maceration } \\
\text { times }\left(\mathrm{M}_{1}, \mathrm{M}_{2} \text { and } \mathrm{M}_{3}\right)^{\mathrm{a}}\end{array}$ & 13 & 83 & 270 & \\
\hline \multirow{4}{*}{12} & \multirow{4}{*}{$\begin{array}{c}\text { ethyl } \\
\text { hexadecanoate }\end{array}$} & $\mathrm{T}_{1}$ & $6 \pm 1$ & $17 \pm 2$ & & 12 \\
\hline & & $\mathrm{T}_{2}$ & $14 \pm 1$ & $18 \pm 2$ & $29 \pm 1$ & 20 \\
\hline & & $\mathrm{T}_{3}$ & $32 \pm 2$ & $13 \pm 2$ & $20 \pm 1$ & 22 \\
\hline & & $\begin{array}{l}\text { averages of the different maceration } \\
\text { times }\left(\mathrm{M}_{1}, \mathrm{M}_{2} \text { and } \mathrm{M}_{3}\right)^{\mathrm{a}}\end{array}$ & 17 & 16 & 25 & \\
\hline \multirow{4}{*}{13} & \multirow{4}{*}{ total esters } & $\mathrm{T}_{1}$ & $5874 \pm 42$ & $4718 \pm 218$ & & 5296 \\
\hline & & $\mathrm{T}_{2}$ & $7215 \pm 77$ & $8017 \pm 209$ & $8074 \pm 171$ & 7769 \\
\hline & & $\mathrm{T}_{3}$ & $4712 \pm 201$ & $6657 \pm 103$ & $11710 \pm 436$ & 7693 \\
\hline & & $\begin{array}{l}\text { averages of the different maceration } \\
\text { times }\left(\mathrm{M}_{1}, \mathrm{M}_{2} \text { and } \mathrm{M}_{3}\right)^{\mathrm{a}}\end{array}$ & 5934 & 6464 & 9892 & \\
\hline \multicolumn{7}{|c|}{ Acid $/\left(\mu \mathrm{g} \mathrm{L}^{-1}\right)$} \\
\hline \multirow{4}{*}{14} & \multirow{4}{*}{ acetic acid } & $\mathrm{T}_{1}$ & $355 \pm 39$ & $252 \pm 67$ & & 304 \\
\hline & & $\mathrm{T}_{2}$ & $468 \pm 61$ & $495 \pm 97$ & $542 \pm 37$ & 502 \\
\hline & & $\mathrm{T}_{3}$ & $369 \pm 49$ & $331 \pm 70$ & $266 \pm 42$ & 322 \\
\hline & & $\begin{array}{l}\text { averages of the different maceration } \\
\text { times }\left(\mathrm{M}_{1}, \mathrm{M}_{2} \text { and } \mathrm{M}_{3}\right)^{\mathrm{a}}\end{array}$ & 397 & 359 & 404 & \\
\hline \multirow{4}{*}{15} & \multirow{4}{*}{$\begin{array}{l}\text { 2-methylpropanoic } \\
\text { acid }\end{array}$} & $\mathrm{T}_{1}$ & $186 \pm 1$ & $181 \pm 7$ & & 184 \\
\hline & & $\mathrm{T}_{2}$ & $475 \pm 21$ & $438 \pm 10$ & $441 \pm 13$ & 451 \\
\hline & & $\mathrm{T}_{3}$ & $140 \pm 6$ & $162 \pm 3$ & $165 \pm 6$ & 156 \\
\hline & & $\begin{array}{l}\text { averages of the different maceration } \\
\text { times }\left(\mathrm{M}_{1}, \mathrm{M}_{2} \text { and } \mathrm{M}_{3}\right)^{\mathrm{a}}\end{array}$ & 267 & 260 & 303 & \\
\hline \multirow{4}{*}{16} & \multirow{4}{*}{ butanoic acid } & $\mathrm{T}_{1}$ & $126 \pm 3$ & $126 \pm 28$ & & 126 \\
\hline & & $\mathrm{T}_{2}$ & $116 \pm 8$ & $151 \pm 16$ & $130 \pm 31$ & 132 \\
\hline & & $\mathrm{T}_{3}$ & $126 \pm 10$ & $181 \pm 31$ & $167 \pm 6$ & 158 \\
\hline & & $\begin{array}{l}\text { averages of the different maceration } \\
\text { times }\left(\mathrm{M}_{1}, \mathrm{M}_{2} \text { and } \mathrm{M}_{3}\right)^{\mathrm{a}}\end{array}$ & 123 & 153 & 149 & \\
\hline \multirow{4}{*}{17} & \multirow{4}{*}{$\begin{array}{l}\text { 3-methylbutanoic } \\
\text { acid }\end{array}$} & $\mathrm{T}_{1}$ & $1395 \pm 4$ & $1377 \pm 57$ & & 1386 \\
\hline & & $\mathrm{T}_{2}$ & $1833 \pm 348$ & $1796 \pm 6$ & $1893 \pm 172$ & 1841 \\
\hline & & $\mathrm{T}_{3}$ & $1648 \pm 53$ & $1654 \pm 20$ & $1897 \pm 112$ & 1733 \\
\hline & & $\begin{array}{l}\text { averages of the different maceration } \\
\text { times }\left(\mathrm{M}_{1}, \mathrm{M}_{2} \text { and } \mathrm{M}_{3}\right)^{\mathrm{a}}\end{array}$ & 1625 & 1609 & 1895 & \\
\hline \multirow{4}{*}{18} & \multirow{4}{*}{ hexanoic acid } & $\mathrm{T}_{1}$ & $958 \pm 1$ & $865 \pm 60$ & & 912 \\
\hline & & $\mathrm{T}_{2}$ & $562 \pm 14$ & $565 \pm 20$ & $510 \pm 57$ & 546 \\
\hline & & $\mathrm{T}_{3}$ & $604 \pm 13$ & $620 \pm 13$ & $719 \pm 60$ & 648 \\
\hline & & $\begin{array}{l}\text { averages of the different maceration } \\
\text { times }\left(\mathrm{M}_{1}, \mathrm{M}_{2} \text { and } \mathrm{M}_{3}\right)^{\mathrm{a}}\end{array}$ & 708 & 683 & 615 & \\
\hline \multirow{4}{*}{19} & \multirow{4}{*}{ octanoic acid } & $\mathrm{T}_{1}$ & $3603 \pm 166$ & $3483 \pm 449$ & & 3543 \\
\hline & & $\mathrm{T}_{2}$ & $2274 \pm 137$ & $2137 \pm 196$ & $1914 \pm 180$ & 2108 \\
\hline & & $\mathrm{T}_{3}$ & $2257 \pm 70$ & $1890 \pm 101$ & $2326 \pm 367$ & 2158 \\
\hline & & $\begin{array}{l}\text { averages of the different maceration } \\
\text { times }\left(\mathrm{M}_{1}, \mathrm{M}_{2} \text { and } \mathrm{M}_{3}\right)^{\mathrm{a}}\end{array}$ & 2711 & 2503 & 2120 & \\
\hline & & $\mathrm{T}_{1}$ & $314 \pm 64$ & $169 \pm 9$ & & 242 \\
\hline & & $\mathrm{T}_{2}$ & $295 \pm 39$ & $146 \pm 21$ & $193 \pm 30$ & 211 \\
\hline 20 & nonanoic acid & $\mathrm{T}_{3}$ & $275 \pm 77$ & $130 \pm 32$ & $308 \pm 69$ & 238 \\
\hline & & $\begin{array}{l}\text { averages of the different maceration } \\
\text { times }\left(\mathrm{M}_{1}, \mathrm{M}_{2} \text { and } \mathrm{M}_{3}\right)^{\mathrm{a}}\end{array}$ & 295 & 148 & 251 & \\
\hline
\end{tabular}


Table 3. Concentration of volatile compounds of Syrah wines analyzed with GC-MS and elaborated with grapes coming from different stages of maturation and macerated in distinct periods during vinification (cont.)

\begin{tabular}{|c|c|c|c|c|c|c|}
\hline \multirow[b]{2}{*}{ No. } & \multirow[b]{2}{*}{ Volatile compound } & \multirow[b]{2}{*}{ Ripeness level } & \multicolumn{3}{|c|}{ Maceration time } & \multirow{2}{*}{$\begin{array}{c}\text { Averages of the } \\
\text { different ripeness } \\
\text { levels } \\
\left(\mathrm{T}_{1}, \mathrm{~T}_{2} \text { and } \mathrm{T}_{3}\right)^{\mathrm{a}}\end{array}$} \\
\hline & & & 10 days $\left(\mathrm{M}_{1}\right)$ & 20 days $\left(\mathrm{M}_{2}\right)$ & 30 days $\left(\mathrm{M}_{3}\right)$ & \\
\hline \multirow{4}{*}{21} & \multirow{4}{*}{ decanoic acid } & $\mathrm{T}_{1}$ & $340 \pm 23$ & $473 \pm 73$ & & 407 \\
\hline & & $\mathrm{T}_{2}$ & $148 \pm 23$ & $108 \pm 4$ & $84 \pm 10$ & 113 \\
\hline & & $\mathrm{T}_{3}$ & $102 \pm 7$ & $74 \pm 12$ & $91 \pm 15$ & 89 \\
\hline & & $\begin{array}{l}\text { averages of the different maceration } \\
\text { times }\left(M_{1}, M_{2} \text { and } M_{3}\right)^{\mathrm{a}}\end{array}$ & 197 & 218 & 88 & \\
\hline \multirow{4}{*}{22} & \multirow{4}{*}{ dodecanoic acid } & $\mathrm{T}_{1}$ & $152 \pm 1$ & $127 \pm 9$ & & 140 \\
\hline & & $\mathrm{T}_{2}$ & $99 \pm 15$ & $123 \pm 11$ & $83 \pm 10$ & 102 \\
\hline & & $\mathrm{T}_{3}$ & $66 \pm 4$ & $89 \pm 3$ & $76 \pm 3$ & 77 \\
\hline & & $\begin{array}{l}\text { averages of the different maceration } \\
\text { times }\left(\mathrm{M}_{1}, \mathrm{M}_{2} \text { and } \mathrm{M}_{3}\right)^{\mathrm{a}}\end{array}$ & 106 & 113 & 80 & \\
\hline \multirow{4}{*}{23} & \multirow{4}{*}{ 9-decenoic acid } & $\mathrm{T}_{1}$ & $44 \pm 1$ & $22 \pm 4$ & & 33 \\
\hline & & $\mathrm{T}_{2}$ & $12 \pm 1$ & $20 \pm 3$ & $13 \pm 1$ & 15 \\
\hline & & $\mathrm{T}_{3}$ & $48 \pm 4$ & $25 \pm 1$ & $43 \pm 1$ & 39 \\
\hline & & $\begin{array}{l}\text { averages of the different maceration } \\
\text { times }\left(M_{1}, M_{2} \text { and } M_{3}\right)^{\mathrm{a}}\end{array}$ & 35 & 22 & 28 & \\
\hline \multirow{4}{*}{24} & \multirow{4}{*}{ total acids } & $\mathrm{T}_{1}$ & $7472 \pm 162$ & $7075 \pm 636$ & & 7274 \\
\hline & & $\mathrm{T}_{2}$ & $6282 \pm 245$ & $5978 \pm 214$ & $5804 \pm 455$ & 6021 \\
\hline & & $\mathrm{T}_{3}$ & $5636 \pm 124$ & $5155 \pm 32$ & $6058 \pm 336$ & 5616 \\
\hline & & $\begin{array}{l}\text { averages of the different maceration } \\
\text { times }\left(M_{1}, M_{2} \text { and } M_{3}\right)^{\mathrm{a}}\end{array}$ & 6463 & 6069 & 5931 & \\
\hline \multicolumn{7}{|c|}{ Alcohol / $\left(\mu \mathrm{g} \mathrm{L}^{-1}\right)$} \\
\hline \multirow{4}{*}{25} & \multirow{4}{*}{$\begin{array}{l}\text { 3-methyl- } \\
\text { 1-butanol }\end{array}$} & $\mathrm{T}_{1}$ & $59031 \pm 3983$ & $90670 \pm 5337$ & & 74851 \\
\hline & & $\mathrm{T}_{2}$ & $76272 \pm 12848$ & $94511 \pm 6681$ & $105794 \pm 1882$ & 92192 \\
\hline & & $\mathrm{T}_{3}$ & $63985 \pm 4000$ & $84333 \pm 2045$ & $199 \pm 6$ & 49506 \\
\hline & & $\begin{array}{l}\text { averages of the different maceration } \\
\text { times }\left(\mathrm{M}_{1}, \mathrm{M}_{2} \text { and } \mathrm{M}_{3}\right)^{\mathrm{a}}\end{array}$ & 66429 & 89838 & 52997 & \\
\hline \multirow{4}{*}{26} & \multirow{4}{*}{ (Z)-3-hexen-1-ol } & $\mathrm{T}_{1}$ & $250 \pm 33$ & $425 \pm 29$ & & 338 \\
\hline & & $\mathrm{T}_{2}$ & $193 \pm 7$ & $286 \pm 7$ & $286 \pm 3$ & 255 \\
\hline & & $\mathrm{T}_{3}$ & $128 \pm 3$ & $175 \pm 8$ & $188 \pm 30$ & 164 \\
\hline & & $\begin{array}{l}\text { averages of the different maceration } \\
\text { times }\left(\mathrm{M}_{1}, \mathrm{M}_{2} \text { and } \mathrm{M}_{3}\right)^{\mathrm{a}}\end{array}$ & 190 & 295 & 237 & \\
\hline \multirow{4}{*}{27} & \multirow{4}{*}{ 1-octanol } & $\mathrm{T}_{1}$ & $137 \pm 14$ & $259 \pm 27$ & & 198 \\
\hline & & $\mathrm{T}_{2}$ & $219 \pm 16$ & $273 \pm 26$ & $275 \pm 18$ & 256 \\
\hline & & $\mathrm{T}_{3}$ & $196 \pm 29$ & $251 \pm 6$ & $232 \pm 7$ & 226 \\
\hline & & $\begin{array}{l}\text { averages of the different maceration } \\
\text { times }\left(\mathrm{M}_{1}, \mathrm{M}_{2} \text { and } \mathrm{M}_{3}\right)^{\mathrm{a}}\end{array}$ & 184 & 261 & 254 & \\
\hline \multirow{4}{*}{28} & \multirow{4}{*}{ 1-nonanol } & $\mathrm{T}_{1}$ & $53 \pm 1$ & $218 \pm 53$ & & 136 \\
\hline & & $\mathrm{T}_{2}$ & $139 \pm 30$ & $175 \pm 15$ & $209 \pm 25$ & 174 \\
\hline & & $\mathrm{T}_{3}$ & $110 \pm 27$ & $158 \pm 17$ & $159 \pm 3$ & 142 \\
\hline & & $\begin{array}{l}\text { averages of the different maceration } \\
\text { times }\left(\mathrm{M}_{1}, \mathrm{M}_{2} \text { and } \mathrm{M}_{3}\right)^{\mathrm{a}}\end{array}$ & 101 & 184 & 184 & \\
\hline \multirow{4}{*}{29} & \multirow{4}{*}{ phenyl methanol } & $\mathrm{T}_{1}$ & $47 \pm 8$ & $100 \pm 8$ & & 74 \\
\hline & & $\mathrm{T}_{2}$ & $139 \pm 8$ & $214 \pm 8$ & $263 \pm 28$ & 205 \\
\hline & & $\mathrm{T}_{3}$ & $87 \pm 14$ & $168 \pm 26$ & $210 \pm 33$ & 155 \\
\hline & & $\begin{array}{l}\text { averages of the different maceration } \\
\text { times }\left(\mathrm{M}_{1}, \mathrm{M}_{2} \text { and } \mathrm{M}_{3}\right)^{\mathrm{a}}\end{array}$ & 91 & 161 & 237 & \\
\hline & & $\mathrm{T}_{1}$ & $21049 \pm 2357$ & $31258 \pm 3544$ & & 26154 \\
\hline & & $\mathrm{T}_{2}$ & $32271 \pm 2070$ & $41766 \pm 2132$ & $44658 \pm 972$ & 39565 \\
\hline 30 & 2-phenyl ethanol & $\mathrm{T}_{3}$ & $31619 \pm 1321$ & $45882 \pm 8492$ & $53654 \pm 1583$ & 43718 \\
\hline & & $\begin{array}{l}\text { averages of the different maceration } \\
\text { times }\left(\mathrm{M}_{1}, \mathrm{M}_{2} \text { and } \mathrm{M}_{3}\right)^{\mathrm{a}}\end{array}$ & 28313 & 39365 & 49156 & \\
\hline
\end{tabular}


Table 3. Concentration of volatile compounds of Syrah wines analyzed with GC-MS and elaborated with grapes coming from different stages of maturation and macerated in distinct periods during vinification (cont.)

\begin{tabular}{|c|c|c|c|c|c|c|}
\hline \multirow[b]{2}{*}{ No. } & \multirow[b]{2}{*}{ Volatile compound } & \multirow[b]{2}{*}{ Ripeness level } & \multicolumn{3}{|c|}{ Maceration time } & \multirow{2}{*}{$\begin{array}{c}\text { Averages of the } \\
\text { different ripeness } \\
\text { levels } \\
\left(\mathrm{T}_{1}, \mathrm{~T}_{2} \text { and } \mathrm{T}_{3}\right)^{\mathrm{a}}\end{array}$} \\
\hline & & & 10 days $\left(\mathrm{M}_{1}\right)$ & 20 days $\left(\mathrm{M}_{2}\right)$ & 30 days $\left(\mathrm{M}_{3}\right)$ & \\
\hline \multirow{4}{*}{31} & \multirow{4}{*}{ 1-dodecanol } & $\mathrm{T}_{1}$ & $140 \pm 31$ & $193 \pm 17$ & & 167 \\
\hline & & $\mathrm{T}_{2}$ & $351 \pm 29$ & $267 \pm 78$ & $303 \pm 51$ & 307 \\
\hline & & $\mathrm{T}_{3}$ & $366 \pm 28$ & $255 \pm 74$ & $210 \pm 33$ & 277 \\
\hline & & $\begin{array}{l}\text { averages of the different maceration } \\
\text { times }\left(\mathrm{M}_{1}, \mathrm{M}_{2} \text { and } \mathrm{M}_{3}\right)^{\mathrm{a}}\end{array}$ & 286 & 238 & 257 & \\
\hline \multirow{4}{*}{32} & \multirow{4}{*}{$\begin{array}{l}\text { 4-methyl- } \\
\text { 1-pentanol }\end{array}$} & $\mathrm{T}_{1}$ & $47 \pm 2$ & $71 \pm 6$ & & 59 \\
\hline & & $\mathrm{T}_{2}$ & $19 \pm 1$ & $32 \pm 3$ & $31 \pm 2$ & 27 \\
\hline & & $\mathrm{T}_{3}$ & $26 \pm 2$ & $31 \pm 1$ & $22 \pm 1$ & 26 \\
\hline & & $\begin{array}{l}\text { averages of the different maceration } \\
\text { times }\left(\mathrm{M}_{1}, \mathrm{M}_{2} \text { and } \mathrm{M}_{3}\right)^{\mathrm{a}}\end{array}$ & 31 & 45 & 27 & \\
\hline \multirow{4}{*}{33} & \multirow{4}{*}{$\begin{array}{l}\text { 3-methyl- } \\
\text { 1-pentanol }\end{array}$} & $\mathrm{T}_{1}$ & $49 \pm 1$ & $95 \pm 1$ & & 72 \\
\hline & & $\mathrm{T}_{2}$ & $62 \pm 6$ & $99 \pm 5$ & $199 \pm 5$ & 120 \\
\hline & & $\mathrm{T}_{3}$ & $127 \pm 5$ & $211 \pm 2$ & $215 \pm 16$ & 184 \\
\hline & & $\begin{array}{l}\text { averages of the different maceration } \\
\text { times }\left(\mathrm{M}_{1}, \mathrm{M}_{2} \text { and } \mathrm{M}_{3}\right)^{\mathrm{a}}\end{array}$ & 79 & 135 & 207 & \\
\hline \multirow{4}{*}{34} & \multirow{4}{*}{ 1-hexanol } & $\mathrm{T}_{1}$ & $1219 \pm 96$ & $2745 \pm 138$ & & 1982 \\
\hline & & $\mathrm{T}_{2}$ & $1578 \pm 23$ & $2435 \pm 150$ & $2768 \pm 78$ & 2260 \\
\hline & & $\mathrm{T}_{3}$ & $1706 \pm 33$ & $2239 \pm 99$ & $2511 \pm 158$ & 2152 \\
\hline & & $\begin{array}{l}\text { averages of the different maceration } \\
\text { times }\left(\mathrm{M}_{1}, \mathrm{M}_{2} \text { and } \mathrm{M}_{3}\right)^{\mathrm{a}}\end{array}$ & 1501 & 2473 & 2640 & \\
\hline \multirow{4}{*}{35} & \multirow{4}{*}{ 1-butanol } & $\mathrm{T}_{1}$ & $25 \pm 2$ & $7 \pm 1$ & & 16 \\
\hline & & $\mathrm{T}_{2}$ & $60 \pm 6$ & $99 \pm 1$ & $83 \pm 11$ & 81 \\
\hline & & $\mathrm{T}_{3}$ & $65 \pm 8$ & $110 \pm 2$ & $152 \pm 10$ & 109 \\
\hline & & $\begin{array}{l}\text { averages of the different maceration } \\
\text { times }\left(\mathrm{M}_{1}, \mathrm{M}_{2} \text { and } \mathrm{M}_{3}\right)^{\mathrm{a}}\end{array}$ & 50 & 72 & 118 & \\
\hline \multirow{4}{*}{36} & \multirow{4}{*}{ 2,3-butanediol } & $\mathrm{T}_{1}$ & $173 \pm 13$ & $284 \pm 47$ & & 229 \\
\hline & & $\mathrm{T}_{2}$ & $784 \pm 16$ & $1170 \pm 1$ & $4433 \pm 227$ & 2129 \\
\hline & & $\mathrm{T}_{3}$ & $290 \pm 34$ & $1253 \pm 172$ & $3144 \pm 390$ & 1562 \\
\hline & & $\begin{array}{l}\text { averages of the different maceration } \\
\text { times }\left(\mathrm{M}_{1}, \mathrm{M}_{2} \text { and } \mathrm{M}_{3}\right)^{\mathrm{a}}\end{array}$ & 416 & 902 & 3789 & \\
\hline \multirow{4}{*}{37} & \multirow{4}{*}{ 1,3-butanediol } & $\mathrm{T}_{1}$ & $479 \pm 51$ & $542 \pm 45$ & & 511 \\
\hline & & $\mathrm{T}_{2}$ & $1055 \pm 126$ & $1326 \pm 57$ & $1623 \pm 160$ & 1335 \\
\hline & & $\mathrm{T}_{3}$ & $795 \pm 141$ & $993 \pm 4$ & $1495 \pm 19$ & 1094 \\
\hline & & $\begin{array}{l}\text { averages of the different maceration } \\
\text { times }\left(\mathrm{M}_{1}, \mathrm{M}_{2} \text { and } \mathrm{M}_{3}\right)^{\mathrm{a}}\end{array}$ & 776 & 954 & 1559 & \\
\hline \multirow{4}{*}{38} & \multirow{4}{*}{ 1-hexadecanol } & $\mathrm{T}_{1}$ & $25 \pm 1$ & $53 \pm 5$ & & 39 \\
\hline & & $\mathrm{T}_{2}$ & $46 \pm 7$ & $62 \pm 2$ & $85 \pm 2$ & 64 \\
\hline & & $\mathrm{T}_{3}$ & $48 \pm 10$ & $26 \pm 2$ & $82 \pm 2$ & 52 \\
\hline & & $\begin{array}{l}\text { averages of the different maceration } \\
\text { times }\left(\mathrm{M}_{1}, \mathrm{M}_{2} \text { and } \mathrm{M}_{3}\right)^{\mathrm{a}}\end{array}$ & 40 & 47 & 84 & \\
\hline \multirow{4}{*}{39} & \multirow{4}{*}{ total alcohols } & $\mathrm{T}_{1}$ & $82726 \pm 6462$ & $126920 \pm 7976$ & & 104823 \\
\hline & & $\mathrm{T}_{2}$ & $113189 \pm 12949$ & $142714 \pm 8054$ & $161010 \pm 499$ & 138971 \\
\hline & & $\mathrm{T}_{3}$ & $99549 \pm 4744$ & $136086 \pm 7966$ & $62473 \pm 2083$ & 99369 \\
\hline & & $\begin{array}{l}\text { averages of the different maceration } \\
\text { times }\left(\mathrm{M}_{1}, \mathrm{M}_{2} \text { and } \mathrm{M}_{3}\right)^{\mathrm{a}}\end{array}$ & 98488 & 135240 & 111742 & \\
\hline \multicolumn{7}{|c|}{ Terpene / $\left(\mu \mathrm{g} \mathrm{L}^{-1}\right)$} \\
\hline & & $\mathrm{T}_{1}$ & $9 \pm 1$ & $10 \pm 1$ & & 10 \\
\hline & & $\mathrm{T}_{2}$ & $15 \pm 3$ & $11 \pm 1$ & $17 \pm 5$ & 14 \\
\hline 40 & linalool & $\mathrm{T}_{3}$ & $14 \pm 1$ & $19 \pm 2$ & $13 \pm 1$ & 15 \\
\hline & & $\begin{array}{l}\text { averages of the different maceration } \\
\text { times }\left(M_{1}, M_{2} \text { and } M_{3}\right)^{\mathrm{a}}\end{array}$ & 13 & 13 & 15 & \\
\hline
\end{tabular}


Table 3. Concentration of volatile compounds of Syrah wines analyzed with GC-MS and elaborated with grapes coming from different stages of maturation and macerated in distinct periods during vinification (cont.)

\begin{tabular}{|c|c|c|c|c|c|c|}
\hline \multirow[b]{2}{*}{ No. } & \multirow[b]{2}{*}{ Volatile compound } & \multirow[b]{2}{*}{ Ripeness level } & \multicolumn{3}{|c|}{ Maceration time } & \multirow{2}{*}{$\begin{array}{c}\text { Averages of the } \\
\text { different ripeness } \\
\text { levels } \\
\left(\mathrm{T}_{1}, \mathrm{~T}_{2} \text { and } \mathrm{T}_{3}\right)^{\mathrm{a}}\end{array}$} \\
\hline & & & 10 days $\left(\mathrm{M}_{1}\right)$ & 20 days $\left(\mathrm{M}_{2}\right)$ & 30 days $\left(\mathrm{M}_{3}\right)$ & \\
\hline \multirow{4}{*}{41} & \multirow{4}{*}{ geraniol } & $\mathrm{T}_{1}$ & $6 \pm 1$ & $7 \pm 1$ & & 7 \\
\hline & & $\mathrm{T}_{2}$ & $7 \pm 1$ & $11 \pm 1$ & $12 \pm 1$ & 10 \\
\hline & & $\mathrm{T}_{3}$ & $11 \pm 1$ & $11 \pm 1$ & $11 \pm 1$ & 11 \\
\hline & & $\begin{array}{l}\text { averages of the different maceration } \\
\text { times }\left(\mathrm{M}_{1}, \mathrm{M}_{2} \text { and } \mathrm{M}_{3}\right)^{\mathrm{a}}\end{array}$ & 8 & 10 & 12 & \\
\hline \multirow{4}{*}{42} & \multirow{4}{*}{ (E)-nerolidol } & $\mathrm{T}_{1}$ & $11 \pm 1$ & $11 \pm 1$ & & 11 \\
\hline & & $\mathrm{T}_{2}$ & $12 \pm 1$ & $16 \pm 1$ & $19 \pm 1$ & 16 \\
\hline & & $\mathrm{T}_{3}$ & $15 \pm 1$ & $30 \pm 1$ & $29 \pm 1$ & 25 \\
\hline & & $\begin{array}{l}\text { averages of the different maceration } \\
\text { times }\left(\mathrm{M}_{1}, \mathrm{M}_{2} \text { and } \mathrm{M}_{3}\right)^{\mathrm{a}}\end{array}$ & 13 & 19 & 24 & \\
\hline \multirow{4}{*}{43} & \multirow{4}{*}{ citronellol } & $\mathrm{T}_{1}$ & $10 \pm 0$ & $10 \pm 1$ & & 10 \\
\hline & & $\mathrm{T}_{2}$ & $13 \pm 1$ & $11 \pm 1$ & $10 \pm 1$ & 11 \\
\hline & & $\mathrm{T}_{3}$ & $10 \pm 1$ & $10 \pm 1$ & $11 \pm 1$ & 10 \\
\hline & & $\begin{array}{l}\text { averages of the different maceration } \\
\text { times }\left(\mathrm{M}_{1}, \mathrm{M}_{2} \text { and } \mathrm{M}_{3}\right)^{\mathrm{a}}\end{array}$ & 11 & 10 & 11 & \\
\hline \multirow{4}{*}{44} & \multirow{4}{*}{ total terpenes } & $\mathrm{T}_{1}$ & $36 \pm 1$ & $38 \pm 0$ & & 37 \\
\hline & & $\mathrm{T}_{2}$ & $46 \pm 1$ & $48 \pm 2$ & $58 \pm 6$ & 51 \\
\hline & & $\mathrm{T}_{3}$ & $50 \pm 1$ & $70 \pm 1$ & $64 \pm 1$ & 61 \\
\hline & & $\begin{array}{l}\text { averages of the different maceration } \\
\text { times }\left(\mathrm{M}_{1}, \mathrm{M}_{2} \text { and } \mathrm{M}_{3}\right)^{\mathrm{a}}\end{array}$ & 44 & 52 & 61 & \\
\hline \multirow{4}{*}{45} & \multirow{4}{*}{$\begin{array}{l}\text { 3-(methythio)- } \\
\text { 1-propanol }\end{array}$} & $\mathrm{T}_{1}$ & $189 \pm 6$ & $202 \pm 3$ & & 196 \\
\hline & & $\mathrm{T}_{2}$ & $199 \pm 11$ & $167 \pm 19$ & $305 \pm 9$ & 224 \\
\hline & & $\mathrm{T}_{3}$ & $210 \pm 25$ & $221 \pm 28$ & $215 \pm 16$ & 215 \\
\hline & & $\begin{array}{l}\text { averages of the different maceration } \\
\text { times }\left(\mathrm{M}_{1}, \mathrm{M}_{2} \text { and } \mathrm{M}_{3}\right)^{\mathrm{a}}\end{array}$ & 199 & 197 & 260 & \\
\hline
\end{tabular}

${ }^{a}$ Data are expressed as the average values of three-field replicates \pm standard deviation (SD). The result of each treatment (T or M) also comes as the average of triplicate experiments. The number of digits after decimal point was reported according to the lower SD found for a set of specific numbers of one parameter. $\mathrm{T}_{1}: 113$ days after pruning (DAP); $\mathrm{T}_{2}: 120 \mathrm{DAP} ; \mathrm{T}_{3}: 127 \mathrm{DAP}$.

from $4.5 \%$ for linalool to $19.4 \%$ for diethyl butanedioate and $(E)$-nerolidol. Finally, accuracy for each of the 11 standards ranged from $91.2 \%$ for 2-phenyl ethanol to $119.7 \%$ for hexanoic acid. These values confirm a good performance of the analytical method and agree with the Sanco guidelines. ${ }^{39}$

\section{Volatile compounds quantification on Syrah wines and odor activity value assessment}

Figure 3 presents a striking effect of maturation and maceration on the content of volatiles present in wines that can be seen through very defined and isolated groups, which are formed according to the levels of factors. Figure 3a shows that wines produced with grapes under $\mathrm{T}_{1}$ contained higher levels of (Z)-3-hexen-1-ol (No. 26) and decanoic acid (No. 21), which had significant loadings in PC2 axis. The increase of maturation degree, especially from $T_{1}$ to $\mathrm{T}_{2}$, caused a reduction in the concentration of compounds No. 26 and 21. On the other hand, there was an increase in the content of 2-methylpropanoic acid (No. 15), acetic acid (No. 14), ethyl lactate (No. 4), citronellol (No. 43), 3-methyl-1-butanol (No. 25), from $T_{1}$ to $T_{2}$. Samples from $\mathrm{T}_{3}$ or $\mathrm{T}_{1}$ condition were characterized by having the highest levels of volatiles 9-decenoic acid (No. 23), 9-ethyl decenoate (No. 10), hexanoic acid (No. 18).

The effect of factor $M$ was highly significant as can be seen in Figure 3b, where the loadings of two volatiles (3-methylbutyl acetate, No. 1 and nonanoic acid, No. 20) stand out in relation to others, as maceration length promotes the reduction of their concentrations. In addition, high loadings in the upper left quadrant defined by the negative part of PC1 are also linked to higher concentrations in $\mathrm{M}_{3}$ wines of ester diethyl butanedioate (No. 8), as well as for 2,3-butanediol (No. 36). A similar trend towards higher concentrations in $\mathrm{M}_{2} / \mathrm{M}_{3}$ can be observed for compounds located in the negative axis of PC1: 1-hexanol (No. 34), ethyl tetradecanoate (No. 11), 2-phenyl ethanol (No. 30), 3-methyl-1-pentanol (No. 33), 

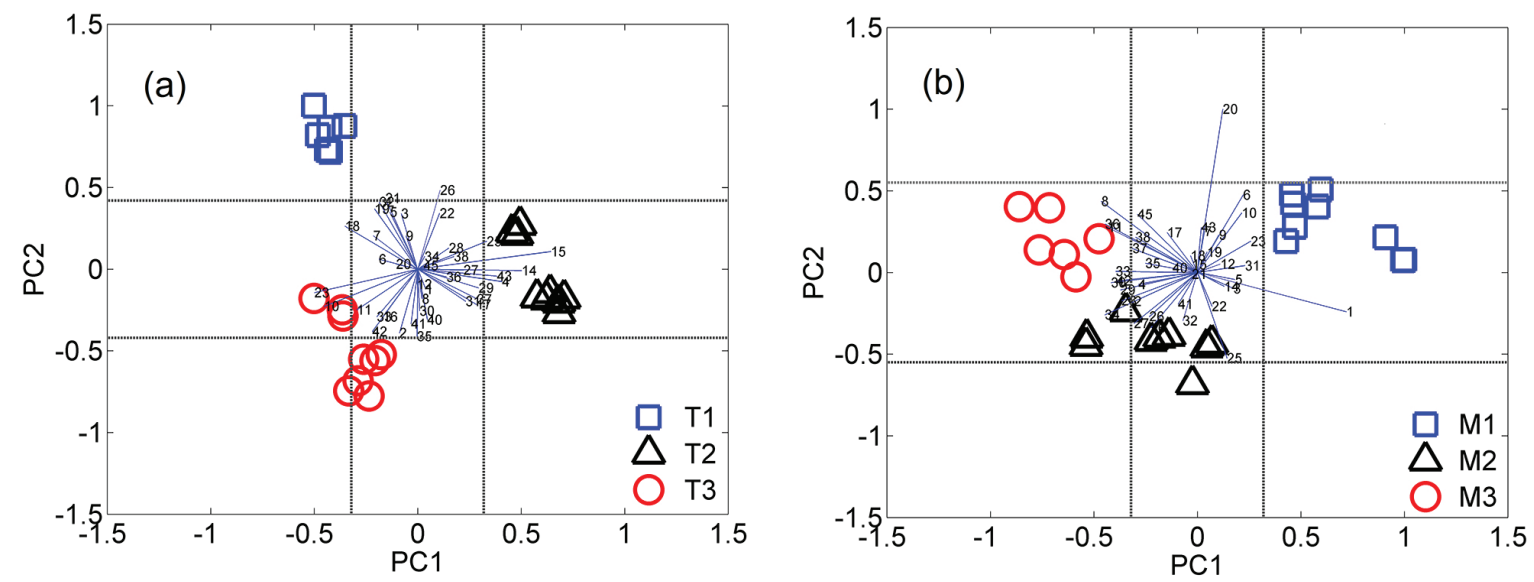

Figure 3. Bi-plot $(\mathrm{PC} 1=21.4 \%$ and for $\mathrm{PC} 2=16.3 \%)$ for volatile compounds of Syrah wines by means of ANOVA-PCA for (a) different degrees of grape maturation (factor $\mathrm{T}$ ) and (b) for distinct lengths of maceration (factor $\mathrm{M})$. $\mathrm{T}_{1}$ stands for $113 \mathrm{DAP}\left(19{ }^{\circ} \mathrm{Brix}\right), \mathrm{T}_{2}$ for $120 \mathrm{DAP}\left(21{ }^{\circ} \mathrm{Brix}\right)$, and $\mathrm{T}_{3}$ for 127 DAP $\left(23^{\circ}\right.$ Brix $)$. $\mathrm{M}_{1}$ designates 10 days of maceration; $\mathrm{M}_{2}, 20 ;$ and $\mathrm{M}_{3}, 30$ days. Loadings that exceed the horizontal and vertical dotted lines are statistically significant.

(E)-nerolidol (No. 42), phenyl methanol (No. 29), and 1-nonanol (No. 28).

The esters Nos. 1, 2, 3, 5 and 8 presented an OAV $>1$. $\mathrm{OAV}$ of ethyl hexanoate (No. 3) ranged from 56.1 in $\mathrm{T}_{1} \mathrm{M}_{1}$ to 13.0 in $\mathrm{T}_{3} \mathrm{M}_{3}$ (fruity, green apple, banana); 3-methylbutyl acetate (No. 1), from 30.7 in $\mathrm{T}_{1} \mathrm{M}_{1}$ to 8.8 in $\mathrm{T}_{3} \mathrm{M}_{3}$ (fruity, banana and sweet); and ethyl octanoate (No. 5), from 4.0 in $\mathrm{T}_{1} \mathrm{M}_{1}$ to 1.6 in $\mathrm{T}_{3} \mathrm{M}_{3}$ (fruity and sweet). They all presented positive contribution to wine aroma and their concentrations were higher in wines made with less mature grapes $\left(T_{1}\right.$, $19^{\circ}$ Brix, Table 3). The concentration of ester No. 1 was reported as ranging from 465 to $508 \mathrm{gg} \mathrm{L}^{-1}$ in Shiraz wines from Australia ${ }^{40}$ and from 458 to $701 \mu \mathrm{g} \mathrm{L}^{-1}$ in Syrah wines from Spain, ${ }^{41}$ data that is in accordance with the present work, where it varied from 1045 in $\mathrm{M}_{1}$ to $363 \mu \mathrm{g} \mathrm{L}^{-1}$ in $\mathrm{M}_{3}$. Longer maceration times might generate a decrease in the concentration of some esters, probably as a result of nonenzymatic hydrolysis. ${ }^{3}$

Conversely, ethyl butanoate (No. 2) showed higher concentration in Syrah wines made with riper grapes $\left(\mathrm{T}_{3}=395 \mu \mathrm{g} \mathrm{L} \mathrm{L}^{-1}, 23^{\circ} \mathrm{Brix}\right)$, imparting its odor of strawberry and apple (higher OAV in $\mathrm{T}_{3} \mathrm{M}_{3}$ 25.1). This same trend has been observed for ester No. 2 in Australian C. Sauvignon wines, where its concentration was $301000 \mu \mathrm{g} \mathrm{L}^{-1}$ in wines made from grapes of $20.3^{\circ} \mathrm{Brix}$ and $474000 \mu \mathrm{g} \mathrm{L}^{-1}$ in wines from grapes of $26.0^{\circ} \mathrm{Brix}$. Concentration range of ethyl butanoate was found to be lower for Syrah wines of the Submiddle São Francisco Valley $\left(75 \mathrm{~T}_{1} \mathrm{M}_{1}\right.$ to $501 \mu \mathrm{g} \mathrm{L^{-1 }}$ $\mathrm{T}_{3} \mathrm{M}_{3}$ ) in comparison with the one found for Australian C. Sauvignon wines. ${ }^{9}$ Diethyl butanedioate (No. 8) followed the same profile as its OAV was less than 1 in $T_{1} M_{1}$ and reached 6.3 in $\mathrm{T}_{3} \mathrm{M}_{3}$ (fruity and melon). Among all these esters, No. 8 was the only one that presented a significant loading on PC1 axis related to maceration and it was also the major ester of Syrah wines. The compounds Nos. 1, 2,3 , and 5 have been reported as important contributors to the overall odor of Australian Shiraz wines due to their higher OAV. ${ }^{40}$ Diethyl butanedioate (No. 8) and ethyl tetradecanoate (No. 11) had their concentrations increased with longer maceration period $\left(\mathrm{M}_{3}\right)$, which is the opposite behavior of 3-methylbutyl acetate (No. 1). Karaoglan red wines from Turkey showed the same trend for both compounds for distinct maceration lengths. ${ }^{10}$

The total concentration of the esters under study raised from 5934 in $\mathrm{M}_{1}$ to $9892 \mu \mathrm{g} \mathrm{L} \mathrm{L}^{-1}$ in $\mathrm{M}_{3}$ and this was mainly due to the increase in the concentration of diethyl butanedioate (No. 8, 1709 in $\mathrm{M}_{1}$ to $5283 \mu \mathrm{g} \mathrm{\textrm {L } ^ { - 1 }}$ in $\mathrm{M}_{3}$ ), which is the major ester of Syrah wines. The general observation that grapes of advanced maturity provide wines with higher concentration of esters has been confirmed for the Syrah tropical wines under study. ${ }^{9}$

Monoterpenes also had influence on wine aroma and among the ones that were quantified in Syrah wines, linalool (No. 40) was the only one that presented OAV $>1$ in some of the Syrah wines [1 $\left(\mathrm{T}_{2} \mathrm{M}_{1}\right), 1.1\left(\mathrm{~T}_{2} \mathrm{M}_{3}\right)$ and $\left.1.3\left(\mathrm{~T}_{3} \mathrm{M}_{2}\right)\right]$. It has been related with citrus, floral and sweet aromas (Table S2, SI section) and its OAV was reported as above odor threshold in Shiraz wines from Australia $(\mathrm{OAV}=1) .^{40}$ Even though it did not have a significant influence on PC loadings, linalool (No. 40) average concentration showed a trend towards higher concentrations with longer harvest date (from 10.0 in $\mathrm{T}_{1}$ to $15.0 \mu \mathrm{g} \mathrm{L}^{-1}$ in $\mathrm{T}_{3}$ ) and this is in agreement with results reported by Šuklje et al. ${ }^{14}$ Their Shiraz wines presented $2.33 \mu \mathrm{g} \mathrm{L}^{-1}$ of linalool when harvested grapes presented soluble solids corresponding to $21{ }^{\circ} \mathrm{Brix}$ and $2.59 \mu \mathrm{g} \mathrm{L} \mathrm{L}^{-1}$ when grapes were collected with $24.6^{\circ} \mathrm{Brix}$. It is reported in literature ${ }^{40}$ as ranging from 13.0 to $15.0 \mu \mathrm{g} \mathrm{L}^{-1}$ in Shiraz wines from Australia. 
In a like manner, a positive contribution of $(E)$-nerolidol (No. 42, rose, apple, green, citrus) may be expected as its concentration increases with longer maceration periods. Its loading was significant in the negative axis of PC1 for maceration factor (Figure 3b).

Some of the alcohols varied significantly with high maceration time, as is the case of 1-nonanol (No. 28), phenyl methanol (No. 29), 2-phenyl ethanol (No. 30), 3-methyl-1-pentanol (No. 33), 1-hexanol (No. 34) and 2,3-butanediol (No. 36), as observed in Table 3 and Figure 3b. They showed the highest average concentrations with $M_{2}$ and $M_{3}$ maceration times, and this result is in accordance with what has been reported in a previous study. ${ }^{3}$ In addition, 3-methyl-1-butanol (No. 25) can be highlighted as its concentration was higher when grapes were harvested with 120 DAP (in Figure 3a its average increased from 74851 in $\mathrm{T}_{1}$ to 92192 in $\mathrm{T}_{2}$ and decreased to $49506 \mu \mathrm{g} \mathrm{L}^{-1}$ in $\mathrm{T}_{3}$ ). It was the major alcohol No. 25 of Syrah wines and its content ranged from a minimum of $199\left(\mathrm{~T}_{3} \mathrm{M}_{3}\right)$ to a maximum of $105794 \mu \mathrm{g} \mathrm{L}^{-1}\left(\mathrm{~T}_{2} \mathrm{M}_{3}\right)$. These levels were lower than those reported in literature data for Australian C. Sauvignon wines during alcoholic fermentation (179000 to $\left.205000 \mu \mathrm{g} \mathrm{L}^{-1}\right)^{9}$ and for Shiraz wines from Australia (161250 to $\left.208400 \mu \mathrm{g} \mathrm{L}^{-1}\right) .^{40}$ The sum of the concentrations of all alcohols presented the same trend observed for 3-methyl-1-butanol (No. 25), according to Table 3. This same alcohol No. 25 also presented a high $\mathrm{OAV}$ [odor described as solvent and nail polish, OAV $2.0\left(\mathrm{~T}_{1} \mathrm{M}_{1}\right)$ to $\left.<1\left(\mathrm{~T}_{3} \mathrm{M}_{3}\right)\right]$ together with 2-phenyl ethanol [No. 30, rose and honey, OAV $1.5\left(\mathrm{~T}_{1} \mathrm{M}_{1}\right)$ to $\left.3.9\left(\mathrm{~T}_{3} \mathrm{M}_{3}\right)\right]$ and 1-hexanol [No. 34, herbaceous and grass, OAV $<1 \mathrm{~T}_{1} \mathrm{M}_{1}$ to $2.3\left(\mathrm{~T}_{3} \mathrm{M}_{3}\right)$ ]. The OAV reported for the same compounds in Australian Shiraz wines were in the range of 5.4-6.9 for 3-methyl-1-butanol, 1.9-4.0 for 2-phenyl ethanol, and $<1$ for 1-hexanol. ${ }^{40}$ Concentrations of alcohols 2-phenyl ethanol [21049 $\left(\mathrm{T}_{1} \mathrm{M}_{1}\right)$ to $53654 \mu \mathrm{g} \mathrm{L}^{-1}\left(\mathrm{~T}_{3} \mathrm{M}_{3}\right)$ ] and 1-hexanol [1219 $\left(\mathrm{T}_{1} \mathrm{M}_{1}\right)$ to $\left.2511 \mu \mathrm{g} \mathrm{L}^{-1}\left(\mathrm{~T}_{3} \mathrm{M}_{3}\right)\right]$ show that they are also major alcohols in Syrah wines. Levels of 2-phenyl ethanol is in agreement with the range reported for Spanish Syrah wines, from 62270 to $85350 \mu \mathrm{g} \mathrm{L}{ }^{-1}$, 11 and also with data published for Australian Shiraz wines (26350 to $\left.56450 \mu \mathrm{g} \mathrm{L}^{-1}\right){ }^{40}$ In a different way, $(Z)$-3-hexen-1-ol (No. 26) achieved maximum concentration in $\mathrm{T}_{1}$ (average from 338 in $\mathrm{T}_{1}$ to $164 \mu \mathrm{g} \mathrm{L}^{-1}$ in $\mathrm{T}_{3}$, Table 3). This agrees with what was reported for C. Sauvignon wines, where grapes harvested with $20.3^{\circ}$ Brix presented higher concentrations of No. $26\left(27.3 \mathrm{mg} \mathrm{L}^{-1}\right)$ than the ones collected with $26^{\circ}$ Brix (3.1 mg L $\left.{ }^{-1}\right){ }^{9}$ Alcohols are usually formed as secondary products of yeast metabolism during winemaking, from sugars or amino acids present in the grape mash $^{3}$ and their content is affected by factors such as fermentation conditions and physicochemical composition of the wine must. C6 alcohols are possibly derived from $\mathrm{C} 18$ fatty acids via lipoxygenase and alcohol dehydrogenase pathways, both during ripening of the grapes, as well as under the oxidative conditions provided during grape crushing. ${ }^{9}$

The total concentration of all acids ranged from 7472 in $\mathrm{T}_{1} \mathrm{M}_{1}$ to $6058 \mu \mathrm{g} \mathrm{L} \mathrm{L}^{-1}$ in $\mathrm{T}_{3} \mathrm{M}_{3}$, with high average for $\mathrm{T}_{1}$ samples (7274 $\left.\mu \mathrm{g} \mathrm{L}^{-1}\right)$, showing lower concentrations in Syrah wines with advanced harvest date. Concentration of octanoic acid (No. 19, 3543 in $\mathrm{T}_{1}$ and $2158 \mu \mathrm{g} \mathrm{L}^{-1}$ in $\mathrm{T}_{3}$ ) was the highest among the acids, and presented the same pattern as total acids, followed by decanoic acid (No. 21, from 407 in $\mathrm{T}_{1} \mathrm{M}_{1}$ to $89 \mu \mathrm{g} \mathrm{\textrm {L } ^ { - 1 }}$ in $\mathrm{T}_{3} \mathrm{M}_{3}$ ), dodecanoic acid (No. 22, from 152 in $\mathrm{T}_{1} \mathrm{M}_{1}$ to $76 \mu \mathrm{g} \mathrm{L}^{-1}$ in $\mathrm{T}_{3} \mathrm{M}_{3}$ ), hexanoic acid (No. 18, 958 in $\mathrm{T}_{1} \mathrm{M}_{1}$ to $719 \mu \mathrm{g} \mathrm{L}^{-1}$ in $\mathrm{T}_{3} \mathrm{M}_{3}$ ), and acetic acid (No. 14, 355 in $\mathrm{T}_{1} \mathrm{M}_{1}$ and 266 in $\mu \mathrm{g} \mathrm{L}^{-1} \mathrm{~T}_{3} \mathrm{M}_{3}$ ). The presence of these acids in red wines have already been reported in the following concentration ranges: hexanoic acid (1023-1461 $\left.\mu \mathrm{g} \mathrm{L}^{-1}\right)$ in Spanish Cabernet Sauvignon, Syrah and Monastrell; ${ }^{41}$ acetic acid (680000-510000 $\left.\mu \mathrm{g} \mathrm{L}^{-1}\right)$ and decanoic acid (224-350 $\mu \mathrm{g} \mathrm{L}^{-1}$ ) in Shiraz wines from Australia. ${ }^{40}$ Some acids presented different concentration profiles as the degree of grape maturation was enhanced, such as 2-methylpropanoic acid (No. 15) and acetic acid (No. 14), that achieved a maximum when grapes were harvested with 120 DAP $\left(\mathrm{T}_{2}\right)$. Conversely, 9-decenoic acid (No. 23) and hexanoic acid (No. 18) presented lower concentrations in $\mathrm{T}_{2}$ wines. These four acids played an important role in the separation of $T_{1}, T_{2}$ and $T_{3}$ wine clusters as can be seen by their loadings in Figure $3 \mathrm{a}$.

The acids with the greatest contribution to the aroma of the Syrah wines were: Nos. 17, 18, 19 and 23, as they presented OAV > 1 (Table S2, SI section): 3-methylbutanoic acid [No. 17, rancid, acid, OAV $42.3\left(\mathrm{~T}_{1} \mathrm{M}_{1}\right)$ to $57.5\left(\mathrm{~T}_{3} \mathrm{M}_{3}\right)$ ], hexanoic acid [No. 18, cheese, fatty, OAV from $2.3\left(\mathrm{~T}_{1} \mathrm{M}_{1}\right)$ to $1.7\left(\mathrm{~T}_{3} \mathrm{M}_{3}\right)$ ], octanoic acid [No. 19, fatty, rancid, OAV from 7.2 in $\mathrm{T}_{1} \mathrm{M}_{1}$ to 4.7 in $\mathrm{T}_{3} \mathrm{M}_{3}$ ], and 9-decenoic acid (No. 23) (waxy, fatty, OAV 1.1 in $\mathrm{T}_{1} \mathrm{M}_{1}$ to 1.2 in $\mathrm{T}_{3} \mathrm{M}_{1}$ ). According to Mayr et al., ${ }^{40}$ the acids Nos. 17, 18 and 19 contribute with aromas of sweet/cheese, leaf/wood/varnish, butter/almond, respectively, to Shiraz wines. Nonanoic acid (No. 20) was the only acid that had a significant loading in relation to maceration length (Figure $3 b$ ), presenting a decrease in its average concentration in wines macerated for longer periods $\left(\mathrm{M}_{1}=295\right.$ to $\left.\mathrm{M}_{3}=251 \mu \mathrm{g} \mathrm{L}^{-1}\right)$. Acids can be formed by anabolic pathways in yeast or can arise from $\beta$-oxidation of higher fatty acids. Their presence in wines is usually related to unpleasant aromas, although, at low concentrations, they do not have a direct negative effect on wine aroma and flavor. Their concentrations during 
maturation may decrease due to the formation of esters and during the winemaking they may also be consumed by yeasts as carbon source. ${ }^{3}$

Figure S4 (SI section) shows the bi-plot of the interaction of $\mathrm{T}$ versus $\mathrm{M}$ factors. The main contribution of the interaction of the two factors is observed in terms of reduction of the concentration of volatile compounds, such as linalool (No. 40) and ethyl hexadecanoate (No. 12) in wine samples that presented the same levels of both factors $\left[\mathrm{T}_{1} \mathrm{M}_{1}\right.$ (blue circles in Figure $\mathrm{S} 4$, SI section), $\mathrm{T}_{2} \mathrm{M}_{2}$ (green circles) and $\mathrm{T}_{3} \mathrm{M}_{3}$ (grey circles)]. Volatiles Nos. 40 and 12 were far from the vector loadings, but the experiments where maturation and maceration corresponded to cross levels $\left(\mathrm{T}_{1} \mathrm{M}_{2}, \mathrm{~T}_{2} \mathrm{M}_{1}, \mathrm{~T}_{2} \mathrm{M}_{3}, \mathrm{~T}_{3} \mathrm{M}_{1}, \mathrm{~T}_{3} \mathrm{M}_{2}\right)$, their concentrations increased in wines, which is an opposite behavior, as if the crossing of factor levels would bring a compensation that raises their concentrations.

\section{Conclusions}

Grapes harvested with higher degree of maturation (21-23 ${ }^{\circ}$ Brix) and macerated for 30 days during winemaking seemed to be appropriate to produce Syrah wines that contained volatiles with pleasant aromas (some esters, alcohols and terpenes) and high levels of phenolic compounds that are known to provide adequate wine sensory characteristics. A higher degree of grape maturation led to an increase in general physicochemical parameters related to phenolic content and, consequently, to increased color. Some anthocyanins, flavonols, procyanidin A2, linalool (floral), also showed higher concentrations in wines made with riper grapes. Maceration length had no influence on physicochemical parameters of Syrah wines. In general, a longer maceration time (30 days) produced wines with higher levels of flavan-3-ols, gallic acid, a few esters (fruity) and alcohols, $(E)$-nerolidol (floral), while nonanoic acid (unpleasant) reduced its concentration with prolonged maceration.

An HS-SPME-GC-MS analytical method was improved and satisfactorily validated, reaching appropriate levels of linearity, intra- and inter-day precisions, accuracy, limits of detection and quantification and can be useful for further quantification of Syrah wine volatiles or can even be extended to other red wine matrices.

The use of ANOVA-PCA was advantageous because of the possibility of multiple response analysis and showed that $\mathrm{T}$ and $\mathrm{M}$, as well as the interaction between both factors, influenced the composition of volatile compounds of Syrah wines. The characterization of the effect of grape maturation degree and of maceration length on the composition of Syrah wines from Submiddle of
São Francisco Valley is an important contribution for future choices on both matters, besides being useful for the production of good quality wines and representing a significant achievement to reach Geographical Indication and future Denomination of Origin certificates. Further studies are needed to better understand the relation between wine sensory attributes with specific physicochemical, phenolic and volatile compounds and their link with grape maturation degree and maceration period, especially in regard to the influence of these variables on wine stability.

\section{Supplementary Information}

Supplementary information is available free of charge at http://jbcs.sbq.org.br/ as PDF file.

\section{Acknowledgments}

The authors thank the National Council for Scientific and Technological Development (Conselho Nacional de Desenvolvimento Científico e Tecnológico, CNPq), the Coordination for the Improvement of Higher Education Personnel (Coordenação de Aperfeiçoamento de Pessoal de Nível Superior, CAPES), and the Research Support Foundation of Rio Grande do Sul (Fundação de Amparo à Pesquisa do Estado do Rio Grande do Sul, FAPERGS) for financial support and scholarships: J. A. B. (CAPES AUXPE-PROEX 587/2017), É. A. S. S. (CNPq 300335/2015-6 and CNPq BJT 401581/2014-4) and C. A. Z. (CNPq Pq 1D 306067/2016-1). We also acknowledge the supporting projects EMBRAPA SEG 03.13.06.017.00.00, FACEPE APQ-0921.5.07-14 and SIBRATEC/FINEP/FAPEG (01.13.0210.00, IP-Campanha).

\section{References}

1. Coelho, E.; Rocha, S. M.; Barros, A. S.; Delgadillo, I.; Coimbra, M. A.; Anal. Chim. Acta 2007, 597, 257.

2. Ribéreau-Gayon, P.; Dubourdie, D.; Donèche, B.; Lonvaud, A.; Handbook of Enology - The Microbiology of Wine and Vinifications, vol. 1, 2 $2^{\text {nd }}$ ed.; John Wiley \& Sons, Ltda: Chichester, UK, 2006.

3. Petropulos, V. I.; Bogeva, E.; Stafilov, T.; Stefova, M.; Siegmund, B.; Pabi, N.; Lankmayr, E.; Food Chem. 2014, 165, 506.

4. Guth, H.; J. Agric. Food Chem. 1997, 45, 3027.

5. Ferrer-Gallego, R.; Hernández-Hierro, J. M.; Rivas-Gonzalo, J. C.; Escribano-Bailón, M. T.; Anal. Chim. Acta 2012, 732, 73.

6. Cadot, Y.; Caillé, S.; Samson, A.; Barbeau, G.; Cheynier, V.; Anal. Chim. Acta 2012, 732, 91. 
7. Locatelli, M.; Travaglia, F.; Coïsson, J. D.; Bordiga, M.; Arlorio, M.; Eur. Food Res. Technol. 2016, 242, 1057.

8. Kocabey, N.; Yilmaztekin, M.; Hayaloglu, A. A.; J. Food Sci. Technol. 2016, 53, 3557.

9. Bindon, K.; Varela, C.; Kennedy, J.; Holt, H.; Herderich, M.; Food Chem. 2013, 138, 1696.

10. Yilmaztekin, M.; Kocabey, N.; Hayaloglu, A. A.; J. Food Sci. 2015, 80, C556.

11. Sarembaud, J.; Pinto, R.; Rutledge, D. N.; Feinberg, M.; Anal. Chim. Acta 2007, 603, 147.

12. Pinto, L.; Lemos, S. G.; Microchem. J. 2013, 110, 417.

13. Luthria, D. L.; Mukhopadhyay, S.; Robbins, R. J.; Finley, J. W.; Banuelos, G. S.; Harnly, J. M.; J. Agric. Food Chem. 2008, 56, 5457.

14. Šuklje, K.; Zhang, X.; Antalick, G.; Clark, A. C.; Deloire, A.; Schmidtke, L. M.; J. Agric. Food Chem. 2016, 64, 870.

15. Peynaud, E.; Connaissance et Travail $d u$ Vin, $2^{\text {nd }}$ ed.; Dunod: Paris, France, 1997.

16. Organisation Internationale de la Vigne et du Vin (OIV); Recueil des Méthodes Internationales d'Analyse des Vins et des Moûts, 2017; OIV: Paris, France, 2017.

17. Harbertson, J.; Spayd, S.; Am. J. Enol. Vitic. 2006, 57, 280.

18. Singleton, V. L.; Rossi, J. A.; Am. J. Enol. Vitic. 1965, 16, 144.

19. Lee, J.; Durst, R.; Wrolstad, R. E.; J. AOAC Int. 2005, 88, 1269.

20. Natividade, M. M. P.; Corrêa, L. C.; Souza, S. V. C.; Pereira, G. E.; Lima, L. C. D.; Microchem. J. 2013, 110, 665.

21. Welke, J. E.; Zanus, M.; Lazarotto, M.; Schmitt, K. G.; Zini, C. A.; J. Braz. Chem. Soc. 2012, 23, 678.

22. Kováts, E.; Helv. Chim. Acta 1958, 41, 1915.

23. Van Den Dool, H.; Kratz, P. D.; J. Chromatogr. A 1963, 11, 463.

24. Noguerol-Pato, R.; González-Barreiro, C.; Cancho-Grande, B.; Simal-Gándara, J.; Food Chem. 2009, 117, 473.

25. Harrington, P. B.; Vieira, N. E.; Espinoza, J.; Nien, J. K.; Romero, R.; Yergey, A. L.; Anal. Chim. Acta 2005, 544, 118.

26. Zontov, Y. V.; Rodionova, O. Y.; Kucheryavskiy, S. V.; Pomerantsev, A. L.; Chemom. Intell. Lab. Syst. 2017, 167, 23.

27. Yamamoto, H.; Fujimori, T.; Sato, H.; Ishikawa, G.; Kami, K.; Ohashi, Y.; BMC Bioinf. 2014, 15, 51.
28. Leão, P. C. S.; Silva, S. F.; Soares, E. B.; Santos, J. Y. B.; Boletim de Pesquisa e Desenvolvimento - Embrapa Semiárido, No. 114; Embrapa: Petrolina, Brasil, 2013.

29. Van Leeuw, R.; Kevers, C.; Pincemail, J.; Defraigne, J. O.; Dommes, J.; J. Food Compos. Anal. 2014, 36, 40.

30. Gil, M.; Kontoudakis, N.; González, E.; Esteruelas, M.; Forcesca, F.; Canals, J. M.; Zamora, F.; J. Agric. Food Chem. 2012, 60, 7988.

31. Hernándes, M. R.; Curso de Viticultura; Haro: Madrid, Spain, 2004.

32. http://www.planalto.gov.br/ccivil_03/_ato2004-2006/2004/lei/ 110.970.htm, accessed in June 2018.

33. Jackson, R. S.; Wine Science: Principles and Applications, $3^{\text {rd }}$ ed.; Elsevier Inc: San Diego, USA, 2008.

34. Lingua, M. S.; Fabani, M. P.; Wunderlin, D. A.; Baroni, M. V.; Food Chem. 2016, 208, 228.

35. Boido, E.; García-Marino, M.; Dellacassa, E.; Carrau, F.; RivasGonzalo, J. C.; Escribano-Bailón, M. T.; Aust. J. Grape Wine Res. 2011, 17, 383.

36. Plavsa, T.; Jurinjak, N.; Antunovic, D.; Persuric, D.; Ganic, K. K.; Food Technol. Biotechnol. 2012, 50, 152.

37. Gordillo, B.; Baca-Bocanegra, B.; Rodriguez-Pulído, F. J.; González-Miret, M. L.; Estévez, I. G.; Quijana-Morín, N.; Heredia, F. J.; Escribano-Bailón, M. T.; Food Chem. 2016, 206, 249.

38. Monagas, M.; Gómez-Cordovés, C.; Bartolomé, B.; Laureano, O.; Silva, J. M. R.; J. Agric. Food Chem. 2003, 51, 6475.

39. Sanco; Guidance Document on Analytical Quality Control and Method Validation Procedures for Pesticides Residues Analysis in Food and Feed, 2015; National Food Administration: Uppsala, Sweden, 2015.

40. Mayr, C. M.; Geue, J. P.; Holt, H. E.; Pearson, W. P.; Jefrey, D. W.; Francis, I. L.; J. Agric. Food Chem. 2014, 62, 4528.

41. Moreno-Pérez, A.; Vila-López, R.; Fernández-Fernández, J. I.; Martínez-Cutillas, A.; Gil-Muñoz, R.; Food Chem. 2013, 139, 770 .

Submitted: November 23, 2018

Published online: February 25, 2019 